\title{
Crumbling of Amatrice clock tower during 2016 Central Italy seismic sequence: Advanced numerical insights
}

\section{Francesco Clementi}

Dep. of Civil and Building Engineering, and Architecture, Università Politecnica della Marche, via Brecce Bianche, 60131, Ancona, Italy francesco.clementi@univpm.com, bttp://orcid.org/0000-0002-9705-777X

\section{Gabriele Milani}

Dep. of Architecture, Built Environment and Construction Engineering, Politecnico di Milano, P. Leonardo da Vinci 32, 20133, Milano, Italy

gabriele.milani@polimi.it, http://orcid.org/0000-0001-5462-3420

\author{
Angela Ferrante \\ Dep. of Civil and Building Engineering, and Architecture, Università Politecnica della Marche, via Brecce Bianche, 60131, Ancona, Italy \\ a.ferrante@pm.univpm.it
}

\section{Marco Valente}

Dep. of Architecture, Built Environment and Construction Engineering, Politecnico di Milano, Piazza Leonardo da Vinci 32, 20133, Milano, Italy

marco.valente@polimi.it

\section{Stefano Lenci}

Dep. of Civil and Building Engineering, and Architecture, Università Politecnica della Marche, via Brecce Bianche, 60131, Ancona, Italy s.lenci@univpm.it, bttp:/ /orcid.org/0000-0003-3154-7896

ABSTRACT. The dynamic behaviour and the seismic vulnerability of the ancient civic clock tower of Amatrice, dramatically damaged by the last shocks sequence of 2016 that occurred in Central Italy, is studied in this paper by means of advanced 3D numerical analyses with the Non-Smooth Contact Dynamics Method (NSCD). Thus, a discontinuous approach was used to assess the dynamic properties and the vulnerability of the masonry structure, through large displacements regulated by the Signorini's law, concerning the impenetrability between the rigid bodies, and by the Coulomb's law, regarding the dry-friction model. Afterward, different values were assigned to the friction coefficient of the models and real seismic shocks were then applied in nonlinear analyses. The major purpose of this study is to highlight that relevant data on the real structural behaviour of historical masonry may provided through advanced numerical analyses. The comparison between the results of numerical simulation and survey of the existing crack pattern of the bell tower

\section{OPEN $\bigcirc$ ACCESS}

Citation: Clementi, F., Milani, G., Ferrante, A., Valente, M., Lenci, S., Crumbling of Amatrice clock tower during 2016 Central Italy seismic sequence: Advanced numerical insights, Frattura ed Integrità Strutturale, 51 (2020) 313-335.

Received: 15.06 .2019 Accepted: 04.11.2019 Published: 01.01.2020

Copyright: (C) 2020 This is an open access article under the terms of the CC-BY 4.0, which permits unrestricted use, distribution, and reproduction in any medium, provided the original author and source are credited. 
permitted to validate the selected approach. Finally, from results and conclusions provided by this case study, it is possible to affirm that the used methodology may be applied to a wide variety of historical masonry structure in Europe.

KEYwORDS. Masonry Towers; Damage Assessment; Non-Smooth Contact Dynamics Method; Damage Cumulation.

\section{INTRODUCTION}

he damage assessment of historical masonry buildings is one of the most difficult tasks to accomplish in structural mechanics, since this kind of structures is commonly heterogeneous, with complex geometries, irregularities and absence of a box behaviour due to defective connections between different structural parts, in particular walls and floors, that often play a fundamental role. However, the knowledge of the dynamical behaviour is crucial for a reliable seismic vulnerability assessment, which became more and more important due to recent catastrophic earthquakes that stroked Italy in the last few decades (Umbria-Marche 1997-1998, Abruzzo 2009, Emilia-Romagna 2012, Marche-LazioUmbria-Abruzzo 2016) [1-4].

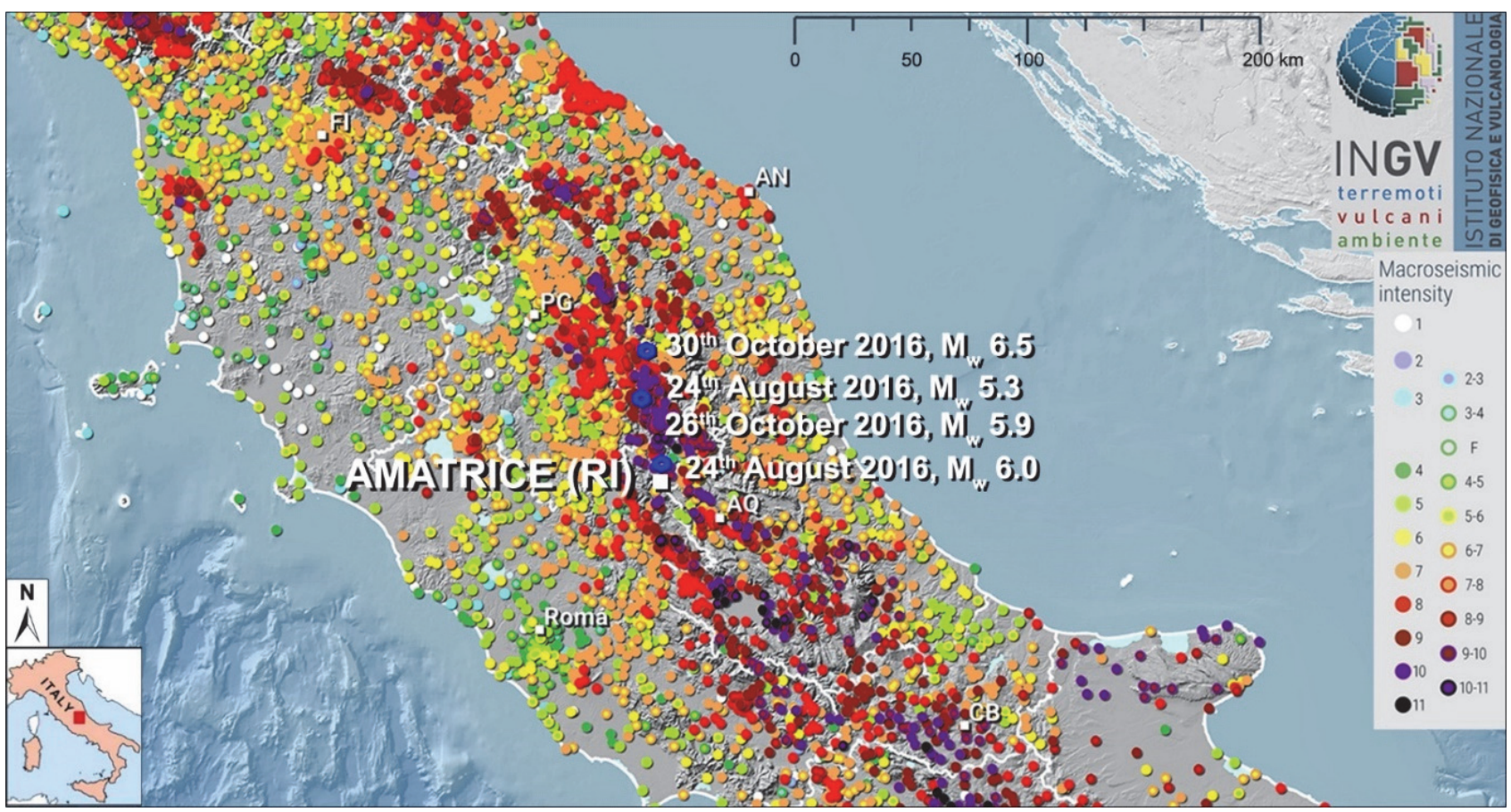

Figure 1: Geographical location of the civic bell tower of Amatrice (Rieti, Italy) and of the epicentres of the four main shocks of the Central Italy seismic sequence of 2016 on the Italian Macro seismic intensity map (https://emidius.mi.ingv.it/)

Towers and belfries are peculiar structural type which characterizes Italian architectural heritage. These structures are distinguished by the poor-quality of local materials which were often deployed, i.e. brick masonry walls that in most cases are non-plastered and bound by poor mortar. Furthermore, these buildings were based on simple architectural forms, with a predominant vertical development. For these reasons, the primary aim is to develop a detailed analysis of interpretative models that can efficaciously predict the behaviour of these structures under seismic actions [5].

To investigate the mechanical behaviour of masonry structures, commonly finite element methods are used, often including very sophisticated constitutive laws taking into account post-elastic behaviours and damage [6-12]. These methods, while being very appealing, do not focus on the possible non-smooth nature of the dynamic response, which can come sliding and impacting between different blocks, a fact that turns out to be common both right before and during the collapse. 
Moreover, the ancient masonry structures may be considered as discontinuous structural systems, which are composed of units (e.g. bricks, stones, blocks, etc.), bonded together with or without mortar [13,14]. Thus, for a numerical model to adequately represent the behaviour of a real structure, both the constitutive model and the input material properties must be selected carefully by the modeler to take into account the variation of masonry properties and the range of stress state types that exist in masonry structures [15-20].

For this reason, the iconic crumbling of the civic bell tower belongs to Amatrice [21], in the province of Rieti in Italy (Fig. 1) is numerically investigated in this study by means of the Non-Smooth Contact Dynamics method (NSCD) which is implemented on a distinct element code [22-24], namely LMGC90 ${ }^{\circ}$.

The NSCD method was applied on advanced numerical models to survey both the dynamical behaviour of the ancient masonry bell tower subject to strong nonlinear dynamic actions and the modalities of progressive collapse mechanisms. Consequently, this characteristic masonry structure inside the epicentral area of the Centre Italy seismic sequence of August and October 2016 was discretized in very detailed 3D models. These models were achieved through rigid blocks bounded together by points of contacts, which follow the Signorini's law, about the impenetrability condition, and the Coulomb's law, relative to dry-friction [25]. Thus, this approach pointed out discontinuous nonlinear dynamics of the structure, allowing to investigate them, exploring the influence of the main mechanical parameters used in the NSCD method, namely the friction coefficient, on the dynamical global behaviour of the structure under the action of the four different sets of ground motions related to most recent Central Italy seismic sequence of 2016.

\section{StRUCTURAL CHARACTERISTICS OF THE AMATRICE's Civic TOWER}

he civic clock tower of Amatrice is the symbol of the city and it is located in the main city's square, namely Cacciatori del Tevere, at the intersection of Via Roma and Corso Umberto I, which are the main streets of the centre (Fig. 2). In fact, there are the Municipal Palace, right in front of the bell tower, and the Church of San Giovanni overlooking the same square and preserving precious frescoes of XV century.
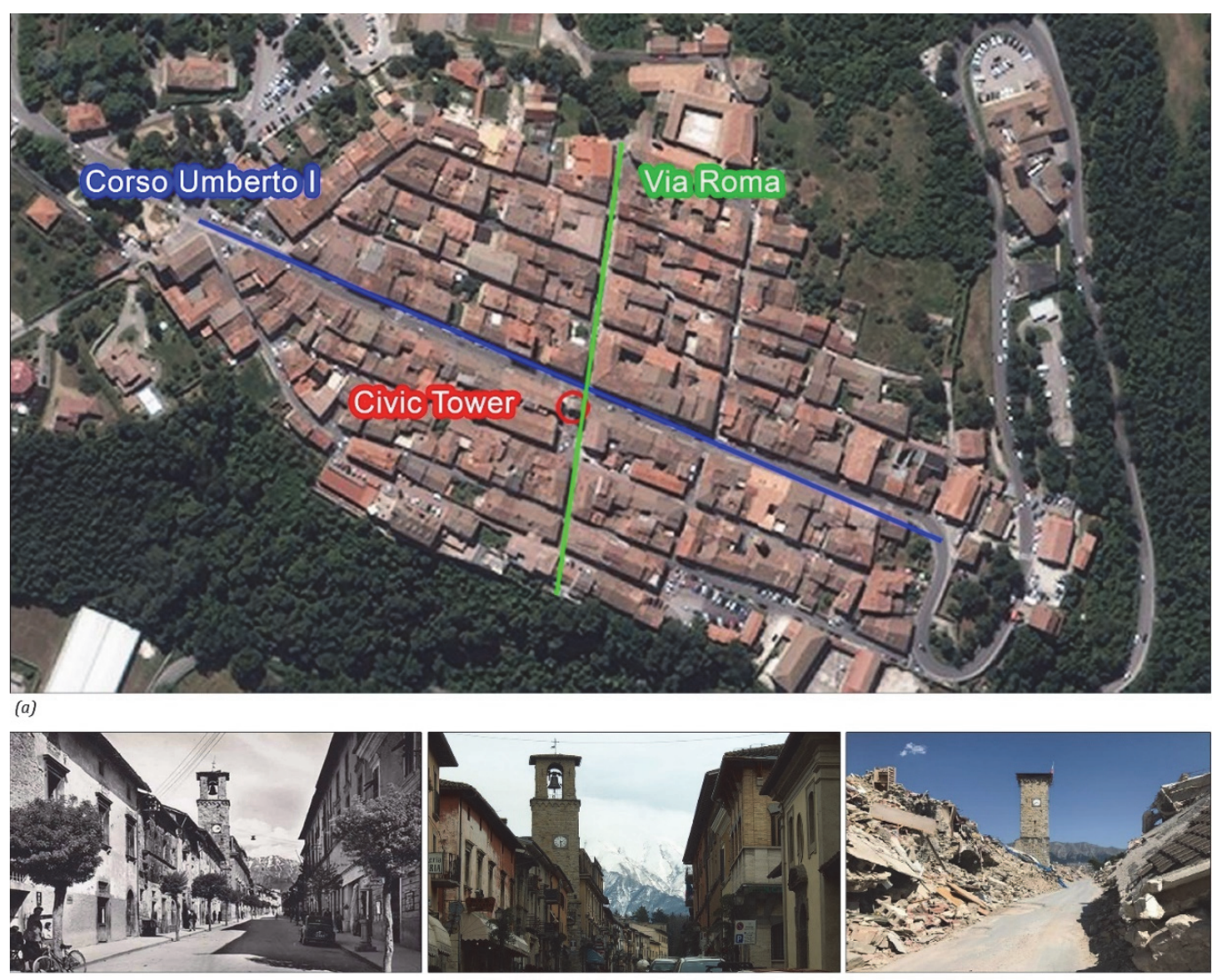

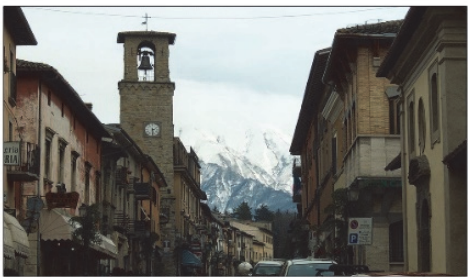

(c)

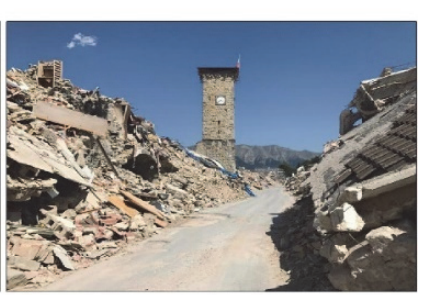

(d)

Figure 2: Location of the civic clock tower inside the historic center of Amatrice (Rieti, Italy) (a), photos of the tower in the past (b), before (c) and after (d) the Central Italy seismic sequence of 2016 
The clock tower dates back to the Middle Ages and there are few historical data about it, since as early as 1293 it was mentioned in ancient documents. The limited historical information reveals that the belfry was built adjacent to the Church of Santa Lucia. In 1684 the feudal lord Alessandro Maria Orsini decided to extend the square and the main street of the city centre. For this reason, the body of the church was destroyed and the tower was modified, with the reinforce of the base and the construction of the annex on its two sides.
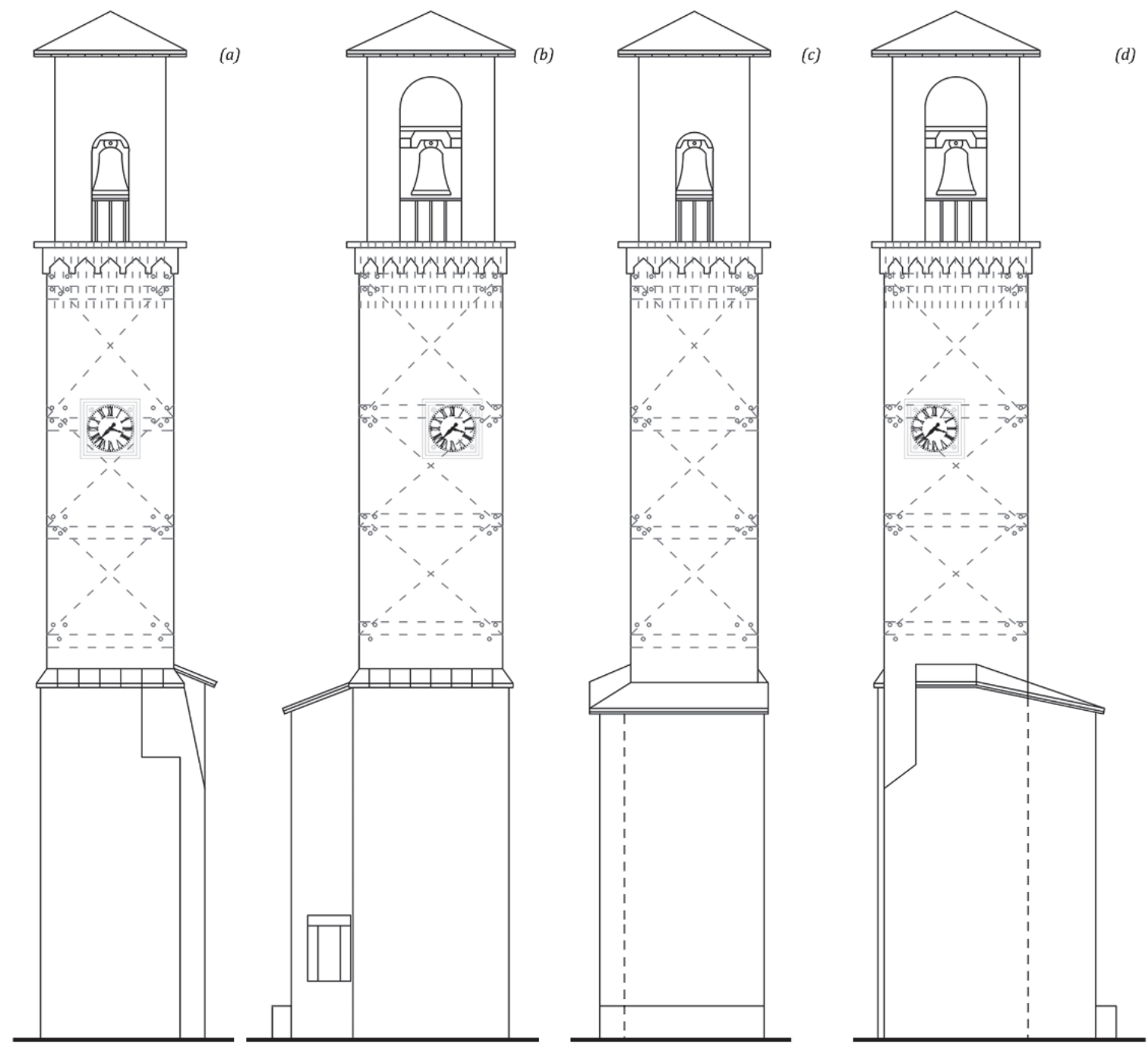

Figure 3: Drawings of the consolidation of the North façade (a), East façade (b), South façade (c), West façade (d) of the Amatrice civic clock tower of the 80 s.

In 1979, the earthquake of the Alta Valnerina (Central Italy) struck the bell tower, with subsequent relevant damages. Therefore, at the beginning of the 80s, the latest retrofitting works were carried out (see Fig. 3). During those restoration works cracks formed due to the weight of the original ancient bell of 1494, thus it was replaced with a lighter bell to remove the high oscillations, about $20 \mathrm{~cm}$ wide, of the vertical structure as in the past. However, the original bell is preserved inside the Church of Madonna of Porta Ferrata.

Moreover, the civic clock tower of Amatrice is about $25 \mathrm{~m}$ high and it has a rectangular plant, with long sides of $4.00 \mathrm{~m} \mathrm{x}$ $5.30 \mathrm{~m}$. As visible in Fig. 4 and Fig. 5, the North and the East façade have deeper base due to the inclination of the ground, respectively of $1.5 \mathrm{~m}$ and $0.60 \mathrm{~m}$.

The entrance to the tower is accessible through the annex, in which are placed the stairs to the upper floors. These stairs are built within the masonry; thus, they were recreated in the 3D discrete models (see Fig. 11). 


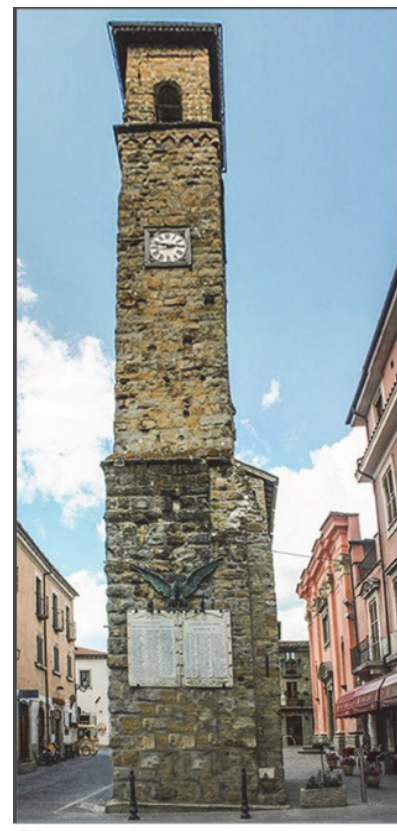

(a)

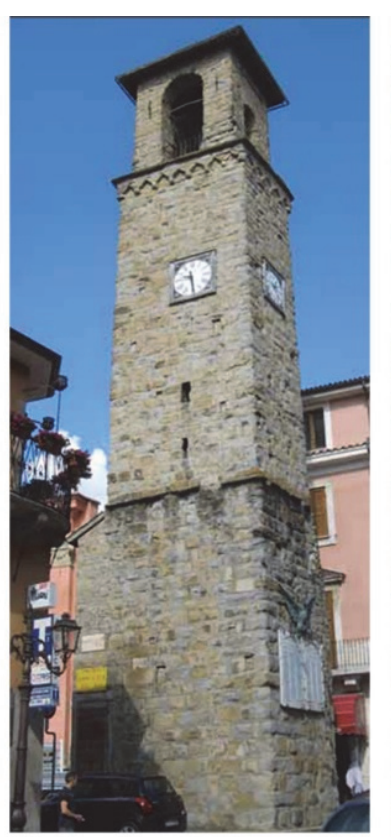

(b)

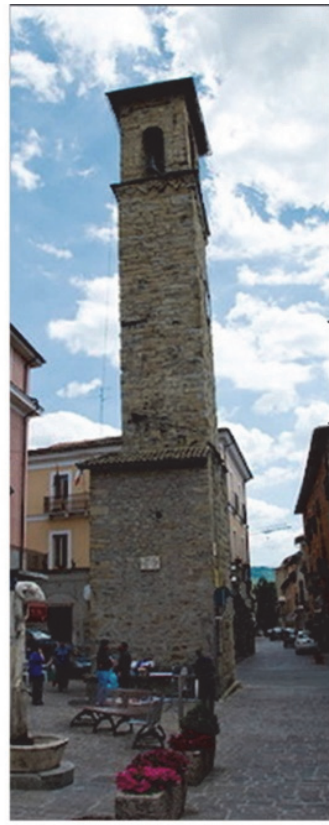

(c)

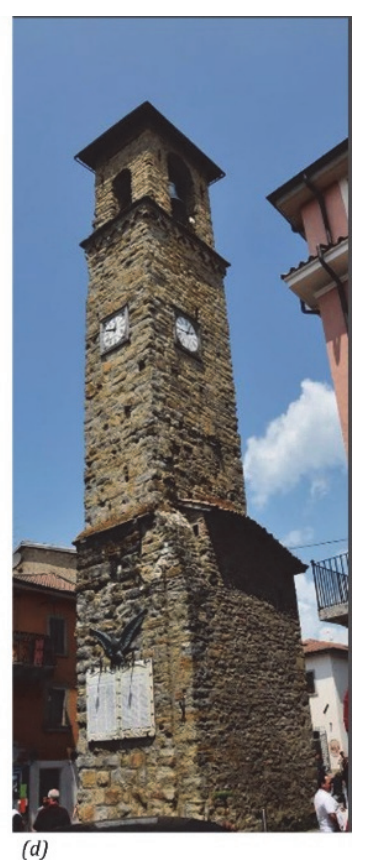

(d)

Figure 4: Views of the façades of the civic clock tower of Amatrice (Rieti, Italy) before the Central Italy seismic sequence of 2016

Furthermore, as clearly visible in Fig. 5, three distinct sections are recognisable along the vertical structure, highlighted by decorative frames and visible reductions of the wall thickness.
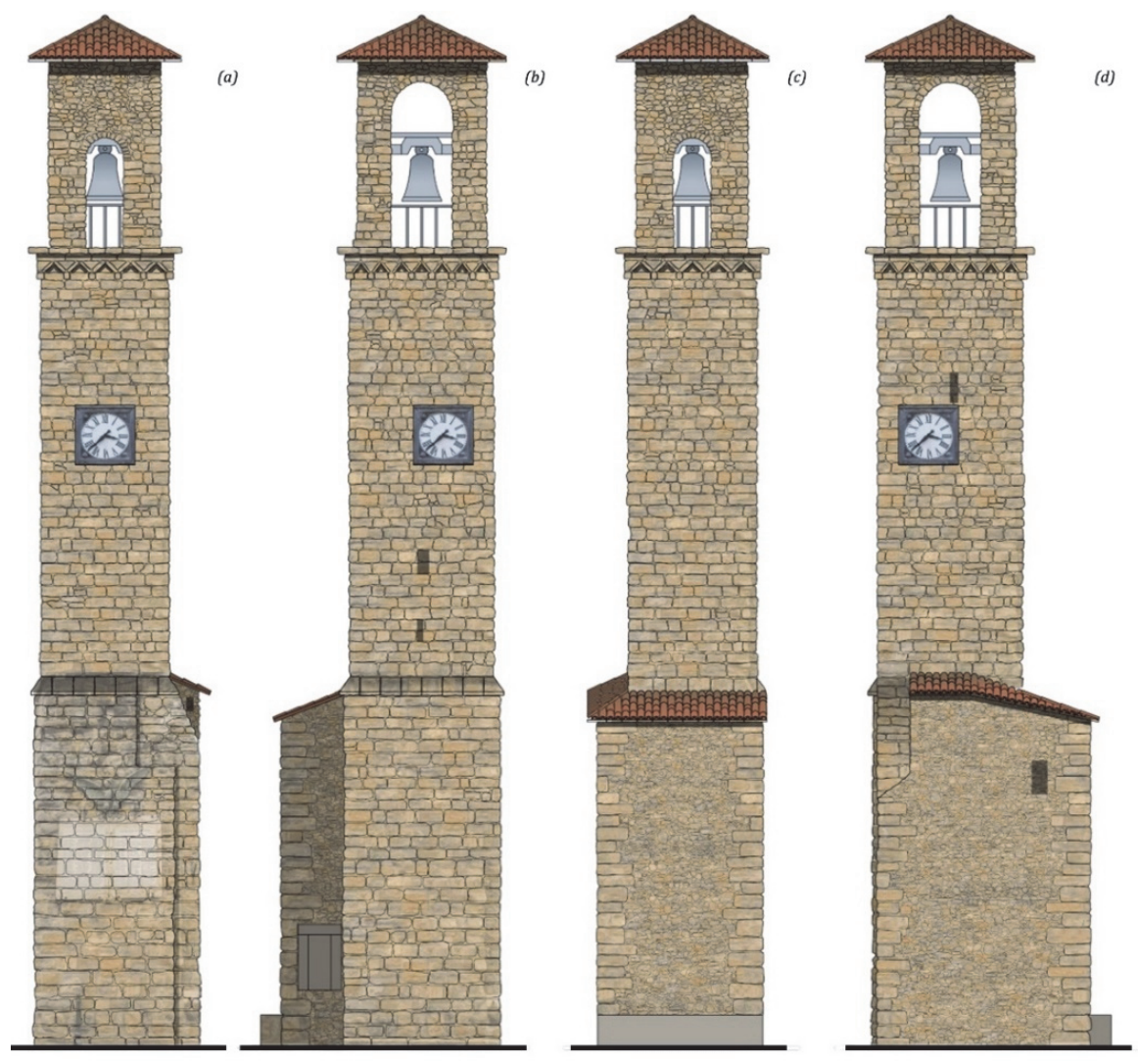

Figure 5: Survey of stones' texture of the North façade (a), East façade (b), South façade (c), West façade (d) of the civic clock tower of Amatrice in the Province of Rieti (Italy) 
The bell tower consists of a first level of about $9 \mathrm{~m}$, composed by smooth stones on the outer side and is based $15 \mathrm{~cm}$ in the wall thickness. Additionally, a second floor is based at $19 \mathrm{~m}$, allowing to access the bell cell from the elevation of the tower. The upper part of the bell tower is about $5 \mathrm{~m}$ high and it rises on four rectangular piers with dimensions of $0.90 \mathrm{x}$ $0.80 \mathrm{~m}$. In fact, the cell bell presents single arched windows on each of the four façades, which have equal pairwise sizes. The civic tower is characterised at its top by a pavilion wooden roof, so as not to overload the masonry walls.

The cell bell and the wooden roof of the civic tower of Amatrice actually collapsed under the destructive actions of the shocks occurred during the Central Italy seismic sequence of 2016. In fact, as reported in Fig. 6, the initial rotation of the piers of the arches began with the first main event of $24^{\text {th }}$ August 2016 then evolved over time under the major shock of the $26^{\text {th }}$ October 2016, until its total collapse due to the strongest event of $30^{\text {th }}$ October 2016.

Moreover, these shocks produced relevant failures of both the annex and the vertical development of the civic tower, but without other important collapses of other parts of the masonry structure.

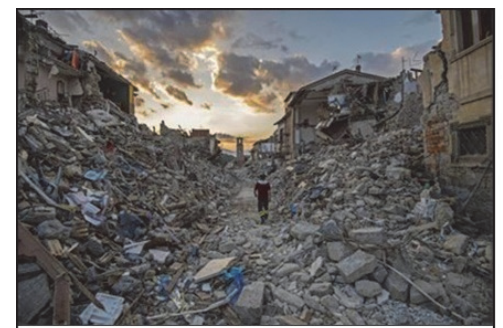

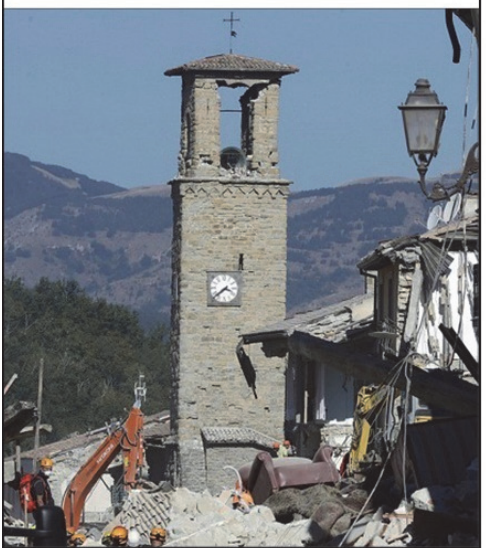

$24^{\text {th }}$ August 2016

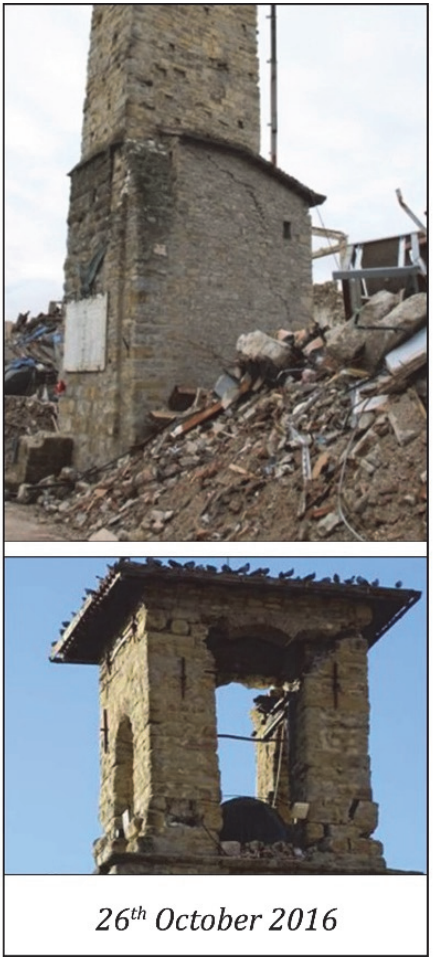

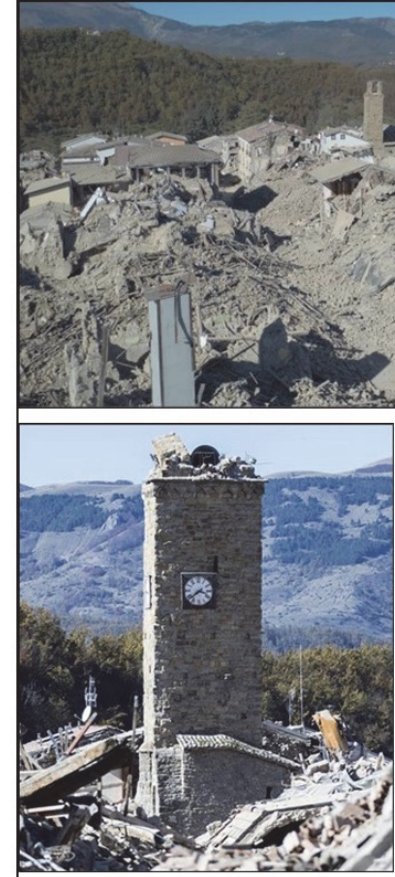

$30^{\text {th }}$ October 2016
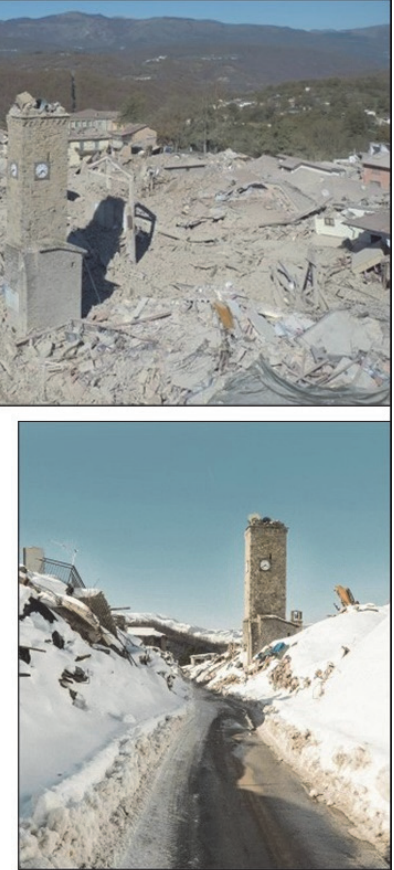

$18^{\text {th }}$ January 2017

Figure 6: Views of the damaged civic clock tower of Amatrice (Rieti, Italy) after the main shocks of the Central Italy seismic sequence of 2016 .

\section{DISTINCT ELEMENT METHOD FOR HISTORICAL MASONRY}

A ncient masonry structures exhibit complex behaviours, due to the heterogeneity and irregularities of their elements and the various material properties that compose them. Hence, for the conservation of the cultural heritage, rich of historical masonry, it becomes crucial to perform accurate modelling and exhaustive assessment of these existing structures.

For this reason, the numerical analyses of masonry buildings are widespread and numerous, according to different approaches. In fact, the most used is macro-modelling, i.e. continuum medium, which takes homogenisation technique into account. However, to recreate the real geometry, with the interaction between distinct blocks, the use of micro-models is the more appropriate, like the Non-Smooth Contact Dynamics Method (NSCD). In fact, this method permits to assess the dynamic global behaviour of the masonry through the local behaviour. Moreover, the interfaces between blocks contain the contact points that allow having frictional behaviour of joints, which are regulated by the Coulomb's law and Signorini's impenetrability.

Hence, to apply the discrete modelling, the LMGC90 ${ }^{\circ}$ open source software was used in this work, which implements the Non-Smooth Contact Dynamics method, with implicit time integration and implicit contact solvers. 
NSCD for masonry structures modelling

The discrete modelling permits to describe the masonry as the interaction between block, assuming that the properties of the bodies and their contact points govern the model. Moreover, the contact is supposed to be punctual and not an area of the interfaces to simplify the process. Other relevant hypotheses assumed in this method are that the bodies are rigid, with the strain applied to the contact points, and the contact forces are provided by the strain at the punctual contact, with independent interactions between bodies.

The approach of the Non-Smooth Contact Dynamics involves first the contact detection, then the contact problem, i.e. the derivation of the contact forces for local scale, and at last the individuation of bodies displacement, for global scale. In fact, in the framework of the NSCD, to compute the multi-contact problem it is necessary to resolve the local unknows, due to the interactions, and the global unknows, due to the bodies. These two sets of unknows are bounding by a mapping (see Fig. 7).

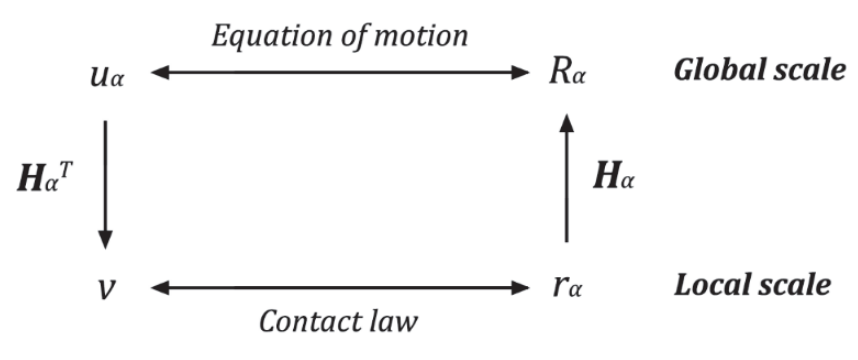

Figure 7: Global and local mapping in the NSCD algorithm

At the contact $\alpha$, a linear mapping $\boldsymbol{H}_{\alpha}$ allow to obtain the global resultant forces related to the local forces $\mathrm{r}_{\alpha}$, with the equation:

$$
\mathrm{R}_{\alpha}=\boldsymbol{H}_{\alpha}(q) r_{\alpha}
$$

$\boldsymbol{H}_{\alpha}(q)$ is a mapping with the local information of the contactors and $q$ is the vector of generalised coordinates of the rigid displacement. Hence, to achieve the global resultant contact forces exerted on bodies:

$$
\mathrm{R}=\sum_{\alpha} \mathrm{R}_{\alpha}
$$

Moreover, to calculate the velocity $u_{\alpha}$ relative to contact in relation with the velocity of the blocks, it can be used the transposed $\boldsymbol{H}_{\alpha}^{T}$ as in this equation:

$$
u_{\alpha}=\boldsymbol{H}_{\alpha}^{T}(q) v
$$

with $v$ is the time derivative of $q$.

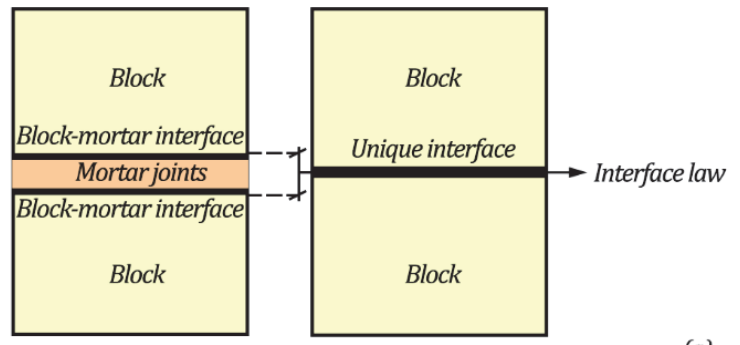

(a)

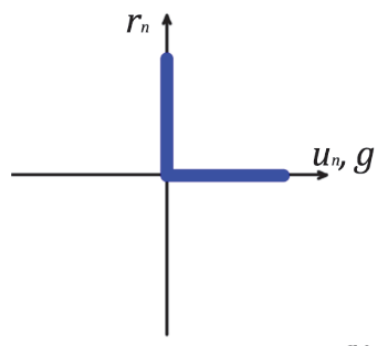

(b)

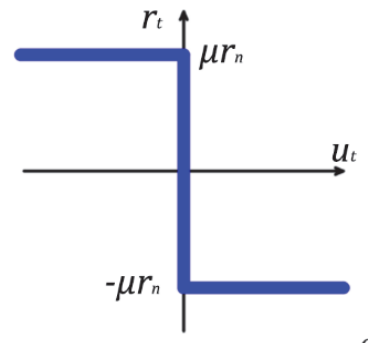

(c)

Figure 8: Contact at the interface between blocks (a), Signorini's impenetrability condition (b), and friction Coulomb's law (c) 
The reaction force and the relative velocity of the contact are described by the laws of Signorini and Coulomb. In fact, the impenetrability of contact between blocks is represented by the Signorini's condition (see Fig. 8 (b)), written as:

$$
\left\{\begin{array}{l}
g \geq 0 \\
r_{n} \geq 0 \\
g \cdot r_{n}=0
\end{array}\right.
$$

where $g$ is the distance between the bodies and $r_{n}$ is the normal component of the contact force. The same equations can be written for the velocities, considering the normal component $u_{n}$, in the following way:

$$
\left\{\begin{array}{l}
g\left(t_{0}\right) \geq 0 \text { at initial time step } t_{0}, \\
g(t) \leq 0 \Rightarrow u_{n} \geq 0, r_{n} \geq 0, u_{n} r_{n}=0
\end{array}\right.
$$

Additionally, the dry friction Coulomb's law (see Fig. 8 (c)) permits to comprehend the tangential force between blocks and the sliding, as written in the following system:

$$
\begin{cases}\left\|u_{T}\right\|=0,\left\|r_{T}\right\|<\mu r_{n} \Rightarrow\left\|u_{T}\right\|=0 & \text { Sticking } \\ \left\|r_{T}\right\|=\mu r_{n} \Rightarrow u_{T}=-k r_{T} \quad k \geq 0,\left\|u_{T}\right\| \neq 0 & \text { Sliding }\end{cases}
$$

where $\mu$ is the friction coefficient.

Thus, the bodies exhibit dynamics regulated by the following equation of motion:

$$
\boldsymbol{M}(q) d v=F(q, v, t) d t+d I
$$

where $\boldsymbol{M}$ is the mass matrix, $F(q, v, t)$ is the vector of internal and external forces of the system, $d t$ is the Lebesgue measure on $\mathbb{R}, \mathrm{d} v$ is a differential measure of velocity denoting the acceleration measure and $d I$ is a differential measure of the impulse of contact resultant.

It is important to highlight that it is not necessary to manage explicitly the contact events in the time-stepping integration scheme, as in the case of the event-driven scheme. The time subdivision is done on intervals [ $\mathrm{ti}$, $\mathrm{ti}+1$ ] of length $\mathrm{h}$ and it is fixed, consequently it is possible to deal with a great number of discontinuities during one-time step, and the contact problem is solved over the range in terms of measures of this interval and not in a point-wise way. Thus, the Eq. (7) can be integrated on each time step, which involves to:

$$
\boldsymbol{M}\left(v_{i+1}-v_{i}\right)=\int_{t_{1}}^{t_{i+1}} F(q, v, t) d t+I_{i+1}
$$

with the velocity $v_{i+1}$ is the approximation of the right limit at the time $t_{i+1}$,

$$
\left\{\begin{array}{l}
v_{i+1}=v_{i}+\boldsymbol{M}^{-1} \int_{t_{1}}^{t_{i+1}} F(q, v, t) d t+\boldsymbol{M}^{-1} I_{i+1}, \\
v_{\text {free }}=v_{i}+\boldsymbol{M}^{-1} \int_{t_{1}}^{t_{i+1}} F(q, v, t) d t,
\end{array}\right.
$$

where $v_{\text {free }}$ is the velocity of the bodies in the absence of contacts. Hence, (9) can be rewritten by means of the Delassus operator $W^{\alpha \beta}$ and the local unknows in this form:

$$
\left\{\begin{array}{c}
v_{i+1}^{\alpha}=v_{\text {loc }, \text { free }}^{\alpha}+W^{\alpha \beta} I^{\alpha}, \\
\text { Contact law }\left(I^{\alpha}, v^{\alpha}\right)=0
\end{array}\right.
$$


and $v_{l o c, \text { free }}^{\alpha}=\boldsymbol{H}^{T \alpha}\left(q_{m}\right) v_{\text {free }}+\sum_{\beta \neq \alpha} W^{\alpha \beta} I^{\alpha}$. Finally, the Non-Linear Gauss Seidel method allows to solve the contact problem.

Therefore, between the discrete element methods, there is the NSCD method, which is characterized by three main points: (i) the non-smooth contact laws are directly integrated inside it, (ii) an implicit integration scheme is implemented and (iii) structural damping are not considered into it. Furthermore, the NSCD method requires some simplifications on the building of models. First of all, the bodies are assumed perfectly rigid and, secondly, the contact laws between blocks are determined by the Signorini's impenetrability condition and by the dry-friction à la Coulomb. Thus, these relations on the contacts involve the perfectly plastic impacts, hence without bounces as a consequence, i.e., a null value of the restitution coefficient in the Newton law. According to it, there is the main advantage of the limited computational complexity derived by the simple modelling of the impacts. Afterward, another relevant benefit due to the perfectly plastic impact is related to the dissipation of energy, which explains the damages of the material and the micro-cracks of the stones after the collisions and, additionally, supports the numerical integration and its stability from a computational point of view. Finally, in these models, the dissipated energy is determined by the involvement of the friction and it does not consider the damping effects, which instead are essential for the continuum models.

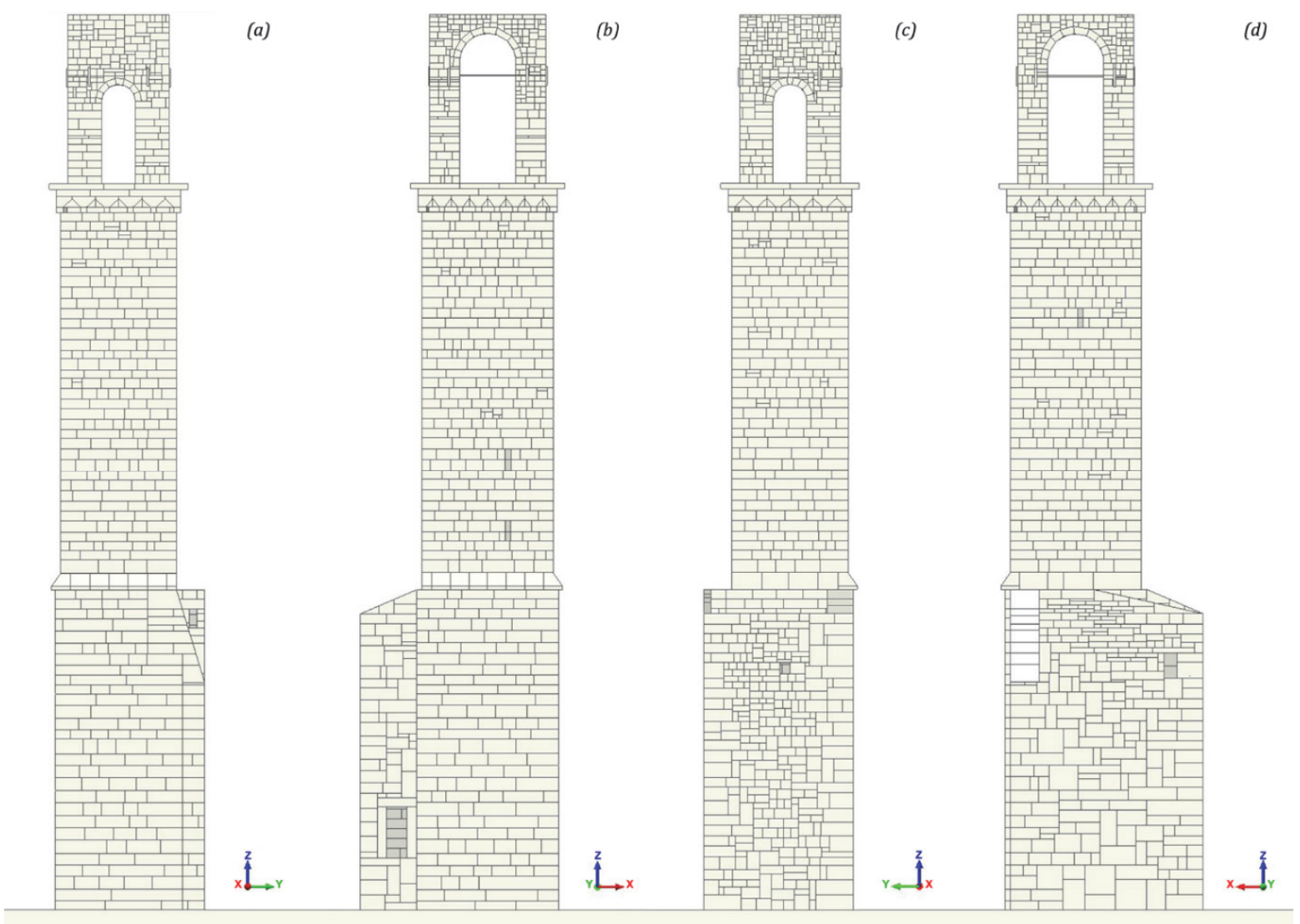

Figure 9: Views of the North façade (a), East façade (b), South façade (c), West façade (d) of the numerical model with steel chains of the civic clock tower of Amatrice (Rieti, Italy) with the NSCD method.

\section{THE CIVIC BELL TOWER'S NUMERICAL MODEL}

he modelling of the Amatrice civic clock tower aims to build the geometry by means of the discontinuous approach, assigning appropriate mechanical properties to the model, thus to appreciate all the possible dynamic behaviour of the masonry under the influence of the friction coefficient between the blocks.

For this reason, the existing configuration of the Amatrice tower was taken into account, with its actual dimensions and the past interventions still present on the masonry structure seriously damaged by the Central Italy seismic sequence of 2016. Thus two numerical models are formed by rigid blocks of different dimensions and regular convex shapes considering (Fig. 
9) and not considering (Fig. 10) steel chains in the bell cell. In this way, it was possible to study the effect of the interventions carried out in the 80 s not only qualitatively but also quantitatively.

The mortar dimension is modelled as well as the bricks into the rigid blocks, assuming the null value of the joints. For what concerns the mass density, it is related to the existing masonry and assumes specific values as indicated in the [26].

Moreover, looking to Fig. 11 it is clear that the wooden floor was modelled, while the masonry panels, the steel chains and the masonry stairs in the annex were recreated as truthful as possible in detail.

Hence, in this perspective, comparing the real masonry of Amatrice in Fig. 5 with the numerical models in Fig. 9 and Fig. 10, it is possible to comprehend the level of detail used for the modelling. In fact, the dimensions used for the blocks correspond to the reliefs done on the masonry textures of the façades. However, the very small and irregular existing stones which characterise the panels of the annex and the upper part of the bell-cell were simplified, focusing on the complexity of the two-leaf masonry. For these reasons, the models are respectively defined by 4388 rigid blocks with different geometries for the models with steel chains and 4401 for the models without steel chains in the bell cell.

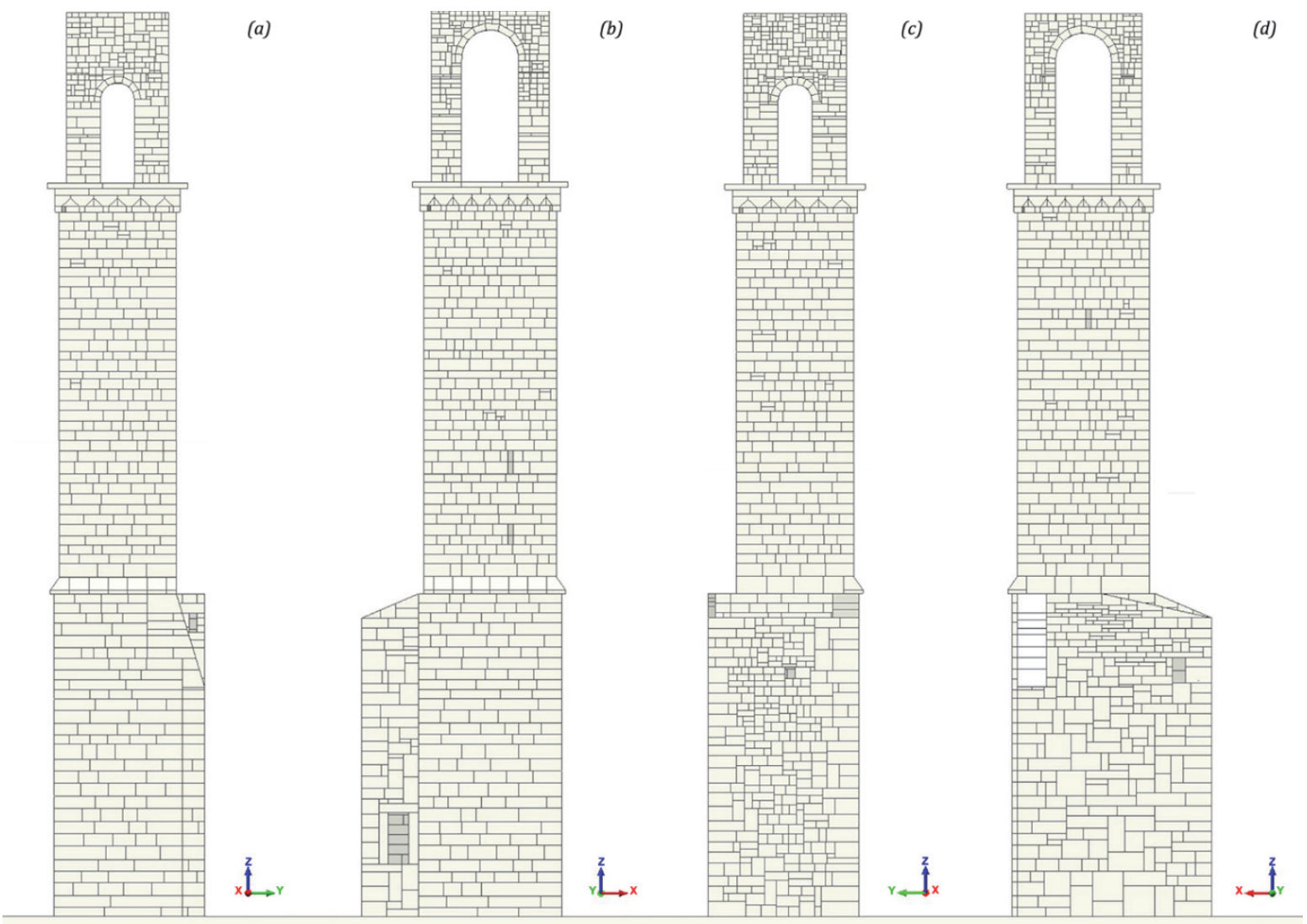

Figure 10: Views of the North façade (a), East façade (b), South façade (c), West façade (d) of the numerical model without steel chains of the civic clock tower of Amatrice (Rieti, Italy) with the NSCD method.

To have a wider view of the damage induced by the 2016 seismic sequence (Fig. 6), in addition to past interventions, attention was paid to the choice of the value of the only material parameter that governs the NSCD method, namely the friction coefficient which is closely related to the quality of the masonry. In fact, the degradation of the mechanical characteristics over time [27], could influence the resistance of the masonry. Hence, for all the blocks along the elevation and of the annex, in both models with and without interventions, the fixed value of the friction was chosen equal to $\mu=$ 0.5 , for simulating a quite good quality of masonry, also thanks to the observation of the damage actually recorded which is present but without clear collapses in these areas. Otherwise, for the modelling of the bell cell, highlighted with a yellow surface in Fig. 11, we used different values of the friction coefficient to investigate the sensitivity of the dynamic response by varying it. For these reasons, the values used are varied between 0.3 and 0.5 with a step of 0.05 to simulate all the possible conditions from bad to good masonry, as reported in Tab. 1. In the same way, these friction values were applied in both models (with and without the steel chains) pointing out a comparison between the bounding effect of the friction in the mortar and the resistant action of the chains on the typical failure mechanisms of the bell cell. 


\begin{tabular}{ccc}
\hline Model & Friction masonry structure & Friction structure - foundation \\
With Steel Chains & 0.30 to 0.5 with increment of 0.05 & 0.90 \\
Without Steel Chains & 0.30 to 0.5 with increment of 0.05 & 0.90 \\
\hline
\end{tabular}

Table 1: Different friction values used for the dynamic nonlinear analyses

However, for the interface between structure and foundation, we assigned a value equal to $\mu=0.90$.

Several analyses were implemented applying first the gravity loads to the system and afterward the different ground accelerations: the dynamical behaviour was elaborated on the shocks' actions of real events imported on the three main directions of the tower base. The main shocks considered have various specifications; all of these are obtained by the records of seismic events occurred with the Central Italy sequence of 2016. In particular, the recordings were taken by the station AMT, which is the nearest to the location of the Amatrice civic clock tower, and in this paper, all its three components, i.e. two on the horizontal and one on the vertical directions, are used. In order to have a better perception of the real damage, we decided not to put at the base of the tower a single time history which, although natural, fails to provide the effect of a sequence composed by the main shock and several aftershocks. With this idea, in this paper it has been considered four shocks events which belong to the seismic sequence of 2016, that took place in the highly active seismological area of Central Italy, where is located the analysed civic tower of Amatrice

(i) 24th August 2016 Amatrice with $\mathrm{M}_{\mathrm{L}}=6.0$ and $\mathrm{M}_{\mathrm{W}}=6.0$ (AMT station in ITACA),

(ii) $24^{\text {th }}$ August 2016 Amatrice with $\mathrm{M}_{\mathrm{L}}=5.4$ and $\mathrm{M}_{\mathrm{W}}=5.3$ (AMT in ITACA),

(iii) $26^{\text {th }}$ October 2016 Amatrice with $\mathrm{M}_{\mathrm{L}}=5.9$ and $\mathrm{M}_{\mathrm{W}}=5.9$ (AMT in ITACA),

(iv) $30^{\text {th }}$ October 2016 Amatrice with $\mathrm{M}_{\mathrm{L}}=6.1$ and $\mathrm{M}_{\mathbb{W}}=6.5$ (AMT in ITACA).

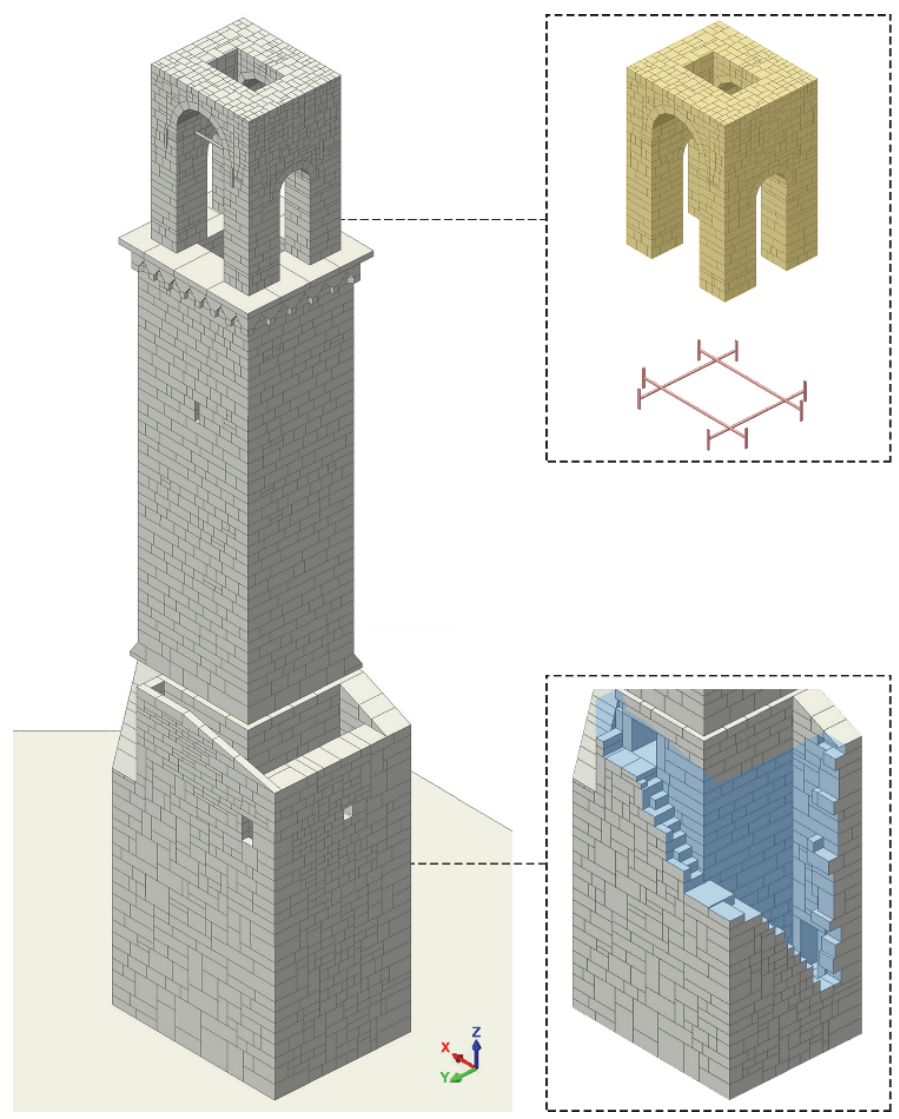

Figure 11: Views of the particular components of the numerical models of the civic clock tower of Amatrice (Rieti, Italy) with the NSCD method.

With the aim to optimize the calculation times without losing information on the induced damage, strong motions of the four Time-Histories (THs) were isolated, which generally have a duration of 10 seconds for each shock, and then applied 
in sequence with a set of null velocities for a 1 second at the beginning, before the first event used, and, in the same way, with other equal sets of null velocities among the other registrations implemented.

The location of the epicentres of the four main shocks and of the civic tower of Amatrice are plotted in Fig. 1, and the comparison between the characteristics of the seismic accelerations is reported in Tab. 2, where [28-30]:

- $\mathrm{R}_{\mathrm{j} b}$, is the Joyner-Boore distance, known as the smallest spacing from the site to the surface projection of the rupture surface;

- $\mathrm{R}_{\mathrm{rup}}$, is the shortest distance between the site and the rupture surface;

- $\mathrm{R}_{\mathrm{ep}}$, is the distance estimated by the geometric swap.

\begin{tabular}{ccccccccccc}
\hline Seismic event & $\mathrm{M}_{\mathrm{L}}$ & $\begin{array}{c}\text { Depth } \\
(\mathrm{km})\end{array}$ & Station & $\begin{array}{c}\text { Class } \\
\mathrm{EC} 8\end{array}$ & $\begin{array}{c}\mathrm{R}_{\mathrm{bb}} \\
{[\mathrm{km}]}\end{array}$ & $\begin{array}{c}\mathrm{R}_{\mathrm{rup}} \\
{[\mathrm{km}]}\end{array}$ & $\begin{array}{c}\mathrm{R}_{\text {epi }} \\
{[\mathrm{km}]}\end{array}$ & $\begin{array}{c}\text { Channel NS } \\
\text { PGA }\left(\mathrm{cm} / \mathrm{s}^{2}\right)\end{array}$ & $\begin{array}{c}\text { Channel EW } \\
\text { PGA }\left(\mathrm{cm} / \mathrm{s}^{2}\right)\end{array}$ & $\begin{array}{c}\text { Channel UD } \\
\text { PGA }\left(\mathrm{cm} / \mathrm{s}^{2}\right)\end{array}$ \\
\hline $24 / 08 / 2016$ & 6.0 & 8.1 & AMT & B $^{*}$ & 1.38 & 4.62 & 8.50 & 368.39 & -850.80 & 391.37 \\
$24 / 08 / 2016$ & 5.4 & 8.0 & AMT & B $^{*}$ & - & - & 20.90 & -93.28 & 105.58 & 63.77 \\
$26 / 10 / 2016$ & 5.9 & 7.5 & AMT & B $^{*}$ & 25.93 & 26.09 & 33.30 & -58.55 & 90.74 & -49.11 \\
$30 / 10 / 2016$ & 6.1 & 9.2 & AMT & B* & 10.12 & 11.49 & 26.40 & 393.63 & 521.62 & 317.82 \\
\hline
\end{tabular}

Table 2: Characteristics of main earthquakes recorded in Amatrice (AMT) station during the main shocks of the Central Italy seismic sequence of 2016, where * indicates that site classification is not based on a direct Vs,30 measurement

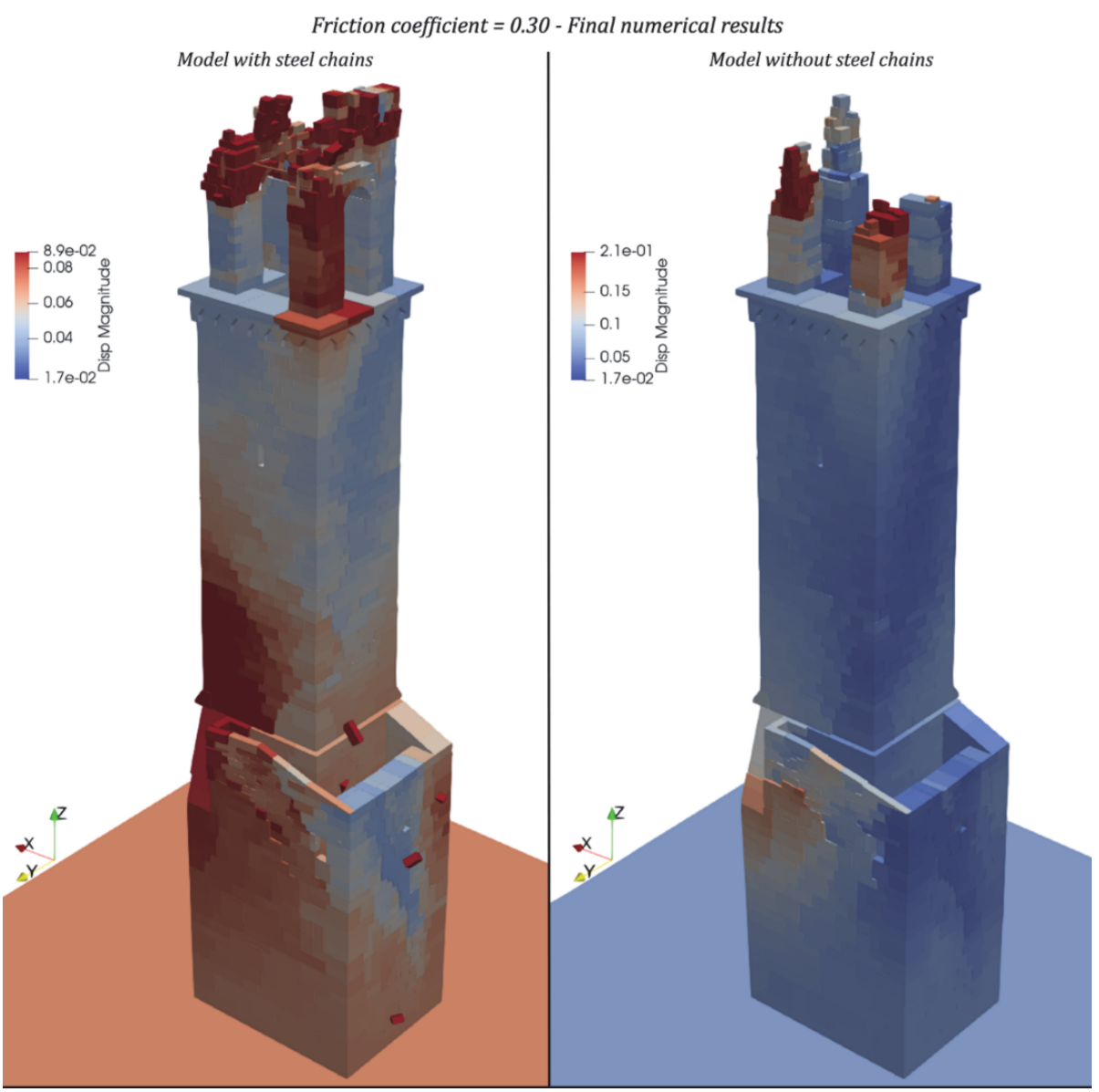

Figure 12: Numerical cumulative damages of the civic clock tower of Amatrice (Rieti, Italy) under the four main shocks recorded in the village during the Central Italy seismic sequence of 2016 for both configurations, with and without the steel chains, and with the friction coefficient equal to 0.30 in the bell cell and 0.50 in the other parts. 


\section{DISCUSSION OF THE NUMERICAL RESULTS}

$\mathrm{T}$

he major results concerning the nonlinear dynamic analyses of the civic tower of Amatrice are introduced in Fig. 12, where the main failure mechanisms at the final step of the cumulative simulations of both models are presented, with and without the steel chains, for a friction values $\mu=0.30$ for the masonry of the bell cell and $\mu=0.50$ for the remaining masonry of the elevation and annex.

In Fig. 12 and moreover in Fig. 13 it clearly appears the effect of steel chains on the masonry arched windows of the bell cell, resisting to the outwards thrust of the arches and the overturning of the piers. Obviously, the multi-leaf masonry of the upper part of the cell bell, made by small stones and mortar with bad quality $(\mu=0.30)$, led to considerable dislocations and rotations of the blocks also in the case of the arches with steel chains.

Moreover, in Fig. 13 is also possible to grasp the impact of the sequence of the strong motion on the masonry structures and their failure mechanisms, with the increment (cumulation) of the numerical damages over time, as in the real collapse. Furthermore, it is important to highlight the influence of previous damages on the dynamical response of the structure and on its capacity to resist to consecutive dynamic actions.

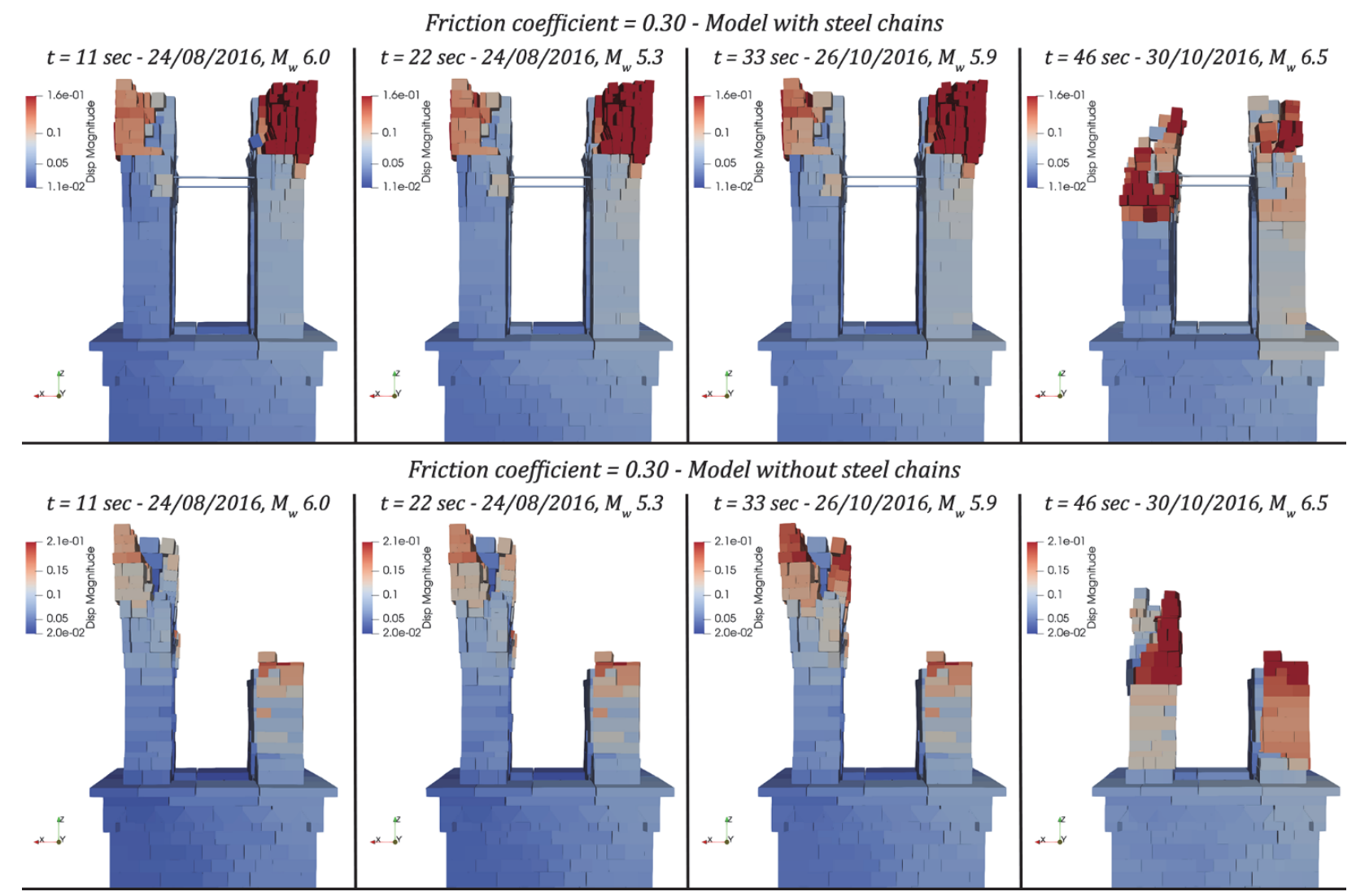

Figure 13: Numerical cumulative damages of the civic clock tower of Amatrice (Rieti, Italy) under the four main shocks recorded in the village during the Central Italy seismic sequence of 2016 for both configurations, with and without the steel chains, and with the friction coefficient equal to 0.30 in the bell cell and 0.50 in the other parts.

\section{The sensitivity of the dynamic response at varying the friction coefficient}

Furthermore, to better investigate the dynamic response of the civic masonry tower of Amatrice, sensitivity analyses were performed by varying the value of the friction coefficient of the bell cell by steps of 0.05 until the $\mu=0.50$. The main results relative to the civic tower of Amatrice and its nonlinear dynamic simulations are reported in Fig. 14, in which are plotted the principal failure configurations at the last step for each of the five seismic analyses at varying the friction coefficient of the masonry of the bell cell with and without steel chains.

As expected, the models with the steel chains exhibit a better dynamic behaviour of the whole bell cell than the tower without the boundary effect of chains, showing less and less damage to the increased friction coefficient of the masonry. 


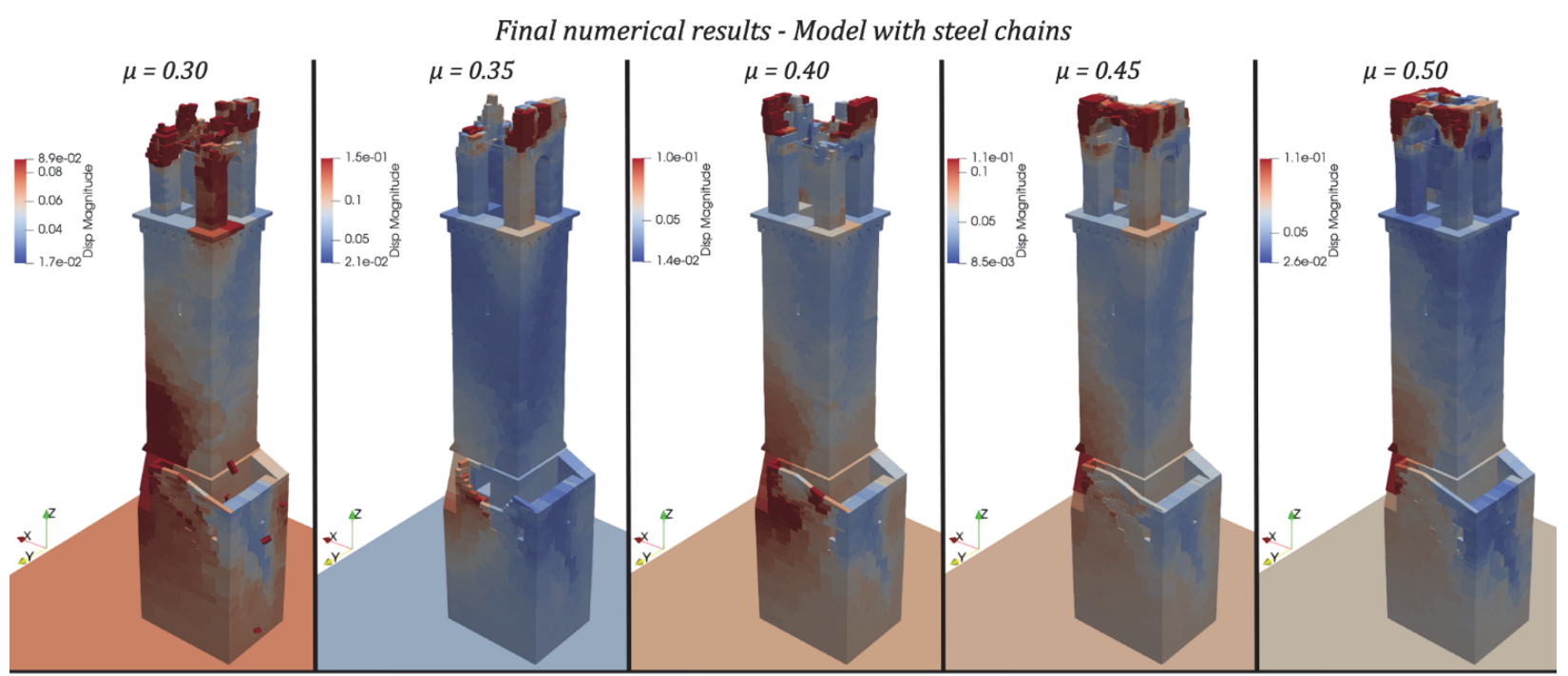

Final numerical results - Model without steel chains

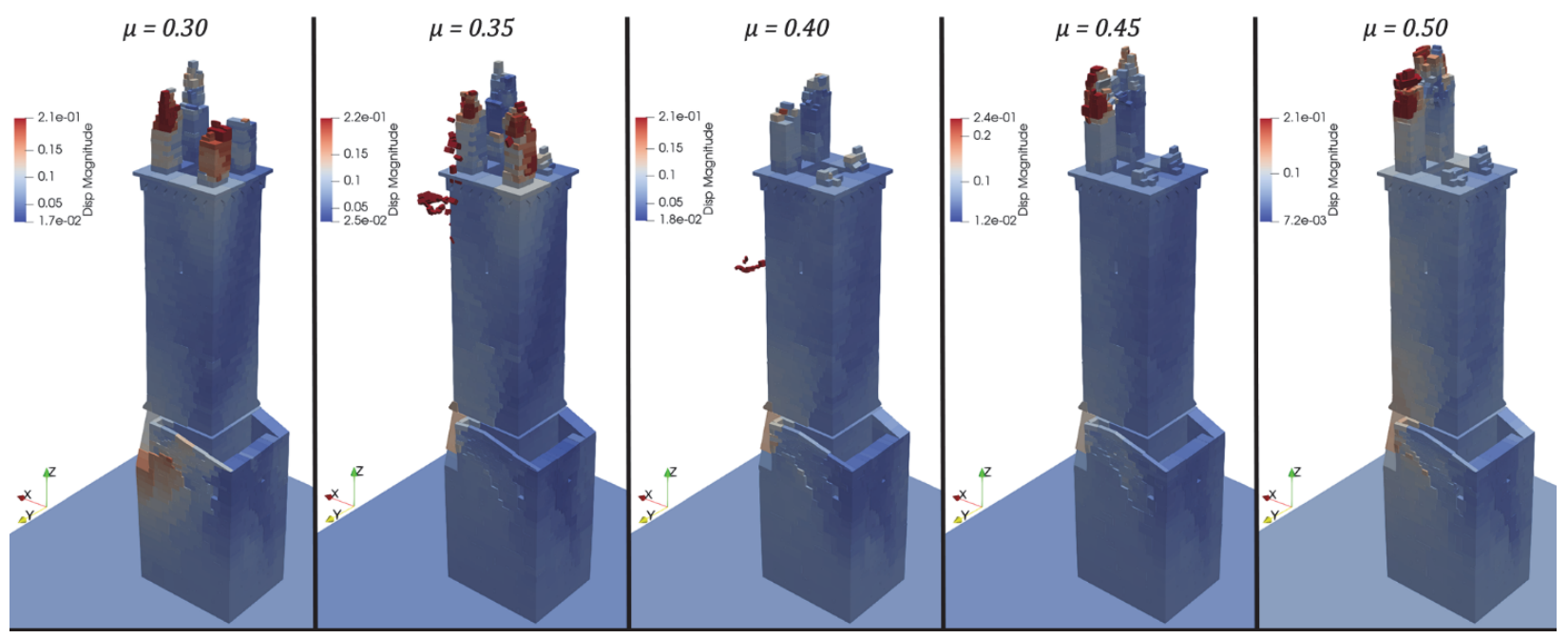

Figure 14: Numerical cumulative damages of the civic tower of Amatrice (Rieti), Italy under the four main shocks recorded in the village during the Central Italy seismic sequence of 2016 for both configurations, with and without the steel chains, at varying of the friction coefficient on the bell cell.

Hence, as visible in the enlargement reported in Fig. 15, the model without the steel chains introduces an early overturning of the piers of the masonry arches, with prevalent dislocations for lower values of the friction, i.e. $\mu=0.30$ and $\mu=0.35$, and with major rotations and complete overturning mechanisms for higher values of the friction, i.e. $\mu=0.40, \mu=0.45$ and $\mu=0.50$.

Moreover, it is important to highlight that the failure of the annex is very similar to the existing crack pattern observed in reality and reported for comparison in Fig. 6.

Additionally, to better understand these failure mechanisms and to appreciate the amplification of the deformations due to the various friction values, it is necessary to know the displacements of the control point \#1 over time plotted in Fig. 16, i.e. related to the upper part of the cell bell of the Amatrice civic tower. In fact, the displacements Time Histories (THs) present the results of the analyses at varying of the friction coefficient for both configurations, with and without the steel chains (respectively namely $\mathrm{C}$, indicated by the solid line, and NC, marked by the dashed line). It confirms the early collapse of the model without chains, for all friction values. At the same time, it is clearly shown how the increasing of the friction, combined with the resistance of the steel chains, improves the capacity of the bell cell to resist mainshock and aftershocks. Furthermore, this model without steel chains and with a friction coefficient equal to 0.30 , during the three initial shocks, shows displacements of circa $18 \div 20 \mathrm{~cm}$ and, by increasing the coefficient until 0.50 the displacements are contained in the range of $6 \div 8 \mathrm{~cm}$. 


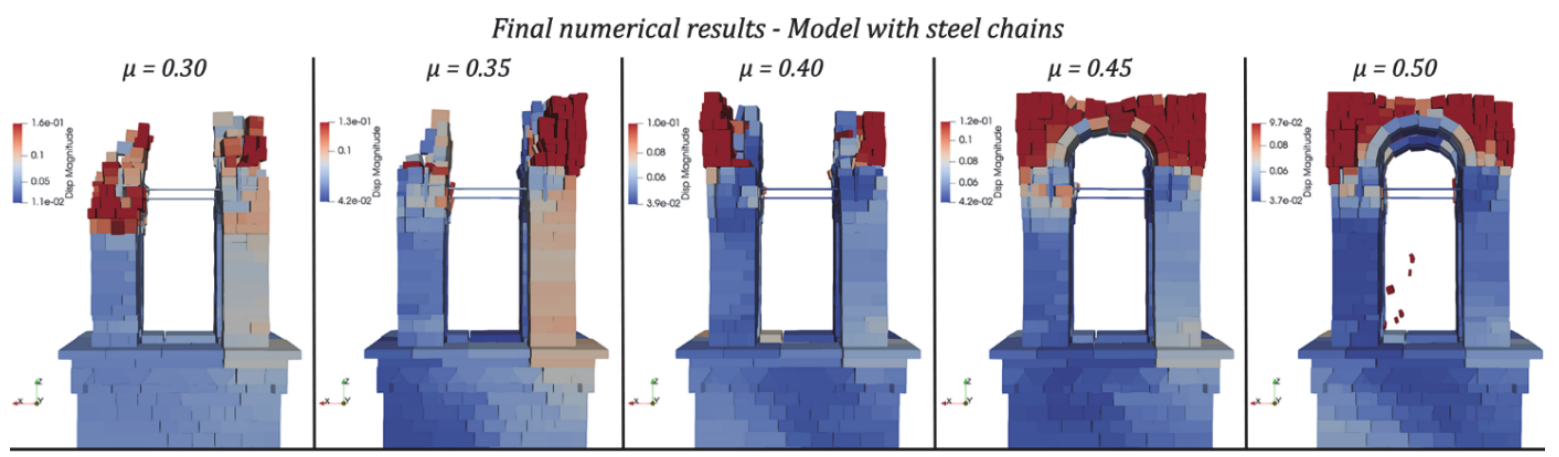

Final numerical results - Model without steel chains

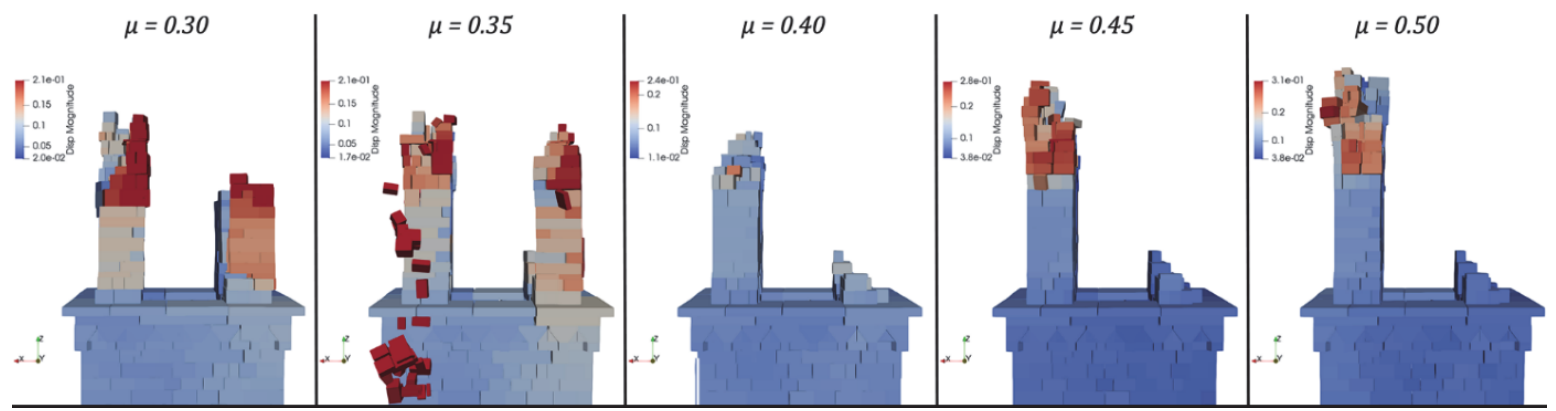

Figure 15: Numerical cumulative damages of the civic clock tower of Amatrice (Rieti, Italy) under the four main shocks recorded in the village during the Central Italy seismic sequence of 2016 for both configurations, with and without the steel chains, at varying of the friction on the bell cell.

For what concerns the displacements THs of the control point \#2 (see Fig. 17), belonging to the upper part of the bell cell on the opposite side of the control point \#1, the dynamic behaviour of the model with the steel chains is similar to the one with the previous control point. Otherwise, the models without the bounding due to the chains resist over time and introduce greater displacements for each friction value considered.

On the other hand, the control point \#3 (see Fig. 18) selected at the base of a masonry pier, presents relevant dislocations and early collapses for the model without the chains at increasing of the friction coefficient, as $\mu=0.40, \mu=0.45$ and $\mu$ $=0.50$. Instead, for the minor friction values, the blocks have important displacements over time, without collapses during the last heavy shock. Similarly, the models with the steel chains introduced lower values of displacements than the other, without final collapses for all friction values.

In fact, by increasing the value of the friction coefficient it is observable that -in general- translation-like mechanisms are substituted with rotation-like mechanisms. Furthermore, the structure will present many sliding surfaces for small values of the friction coefficient, and as this increase, it is possible to note a clear activation of rotation-like mechanisms of the peripheral walls instead, which leads to major displacements and most localized damage along with the tower.

Looking at the displacements THs of the control point \#4, which is at the base of a masonry pier, plotted in Fig. 19, they introduced similar evolution over time, with values near each other. Differently from control points \#1 to \#3, the \#4 presents displacements higher with steel chains and increasing of the friction coefficient, due to the overall behaviour of the bell cell. Lastly, during the final steps of the analyses, there is a change in the dynamic behaviour of the masonry, with an increase of displacements of the model without chains.

For what concerns the THs of the control point \#5 (see Fig. 20), belonging to the annex of the civic tower with fixed friction value equal to 0.50 , they present comparable displacements for all the analyses, with the main values during the final shock of the $30^{\text {th }}$ October.

Lastly, the dissipated energy is plotted for all the models in both configurations, with and without steel chains (respectively $\mathrm{C}$ with a solid line, and $\mathrm{NC}$ with a dotted line), and reported in Fig. 21 at varying of the friction coefficient of the bell cell under the four continuous shocks to investigate cumulative damages. Thus, in the cases of the two events of $24^{\text {th }}$ August 2016 and of $26^{\text {th }}$ October 2016, the higher values of the dissipation of energy belong to the models without the steel chains for all the friction coefficient used. Additionally, the dissipated energy raises at the decreasing of the friction values of the masonry cell bell. Otherwise, the response of the structures at the end of the analysis is different under the action of the strong event of $30^{\text {th }}$ October 2016. In fact, the dissipated energy with friction coefficients equal to 0.45 and 0.50 in this case is higher for the models with steel chains. 


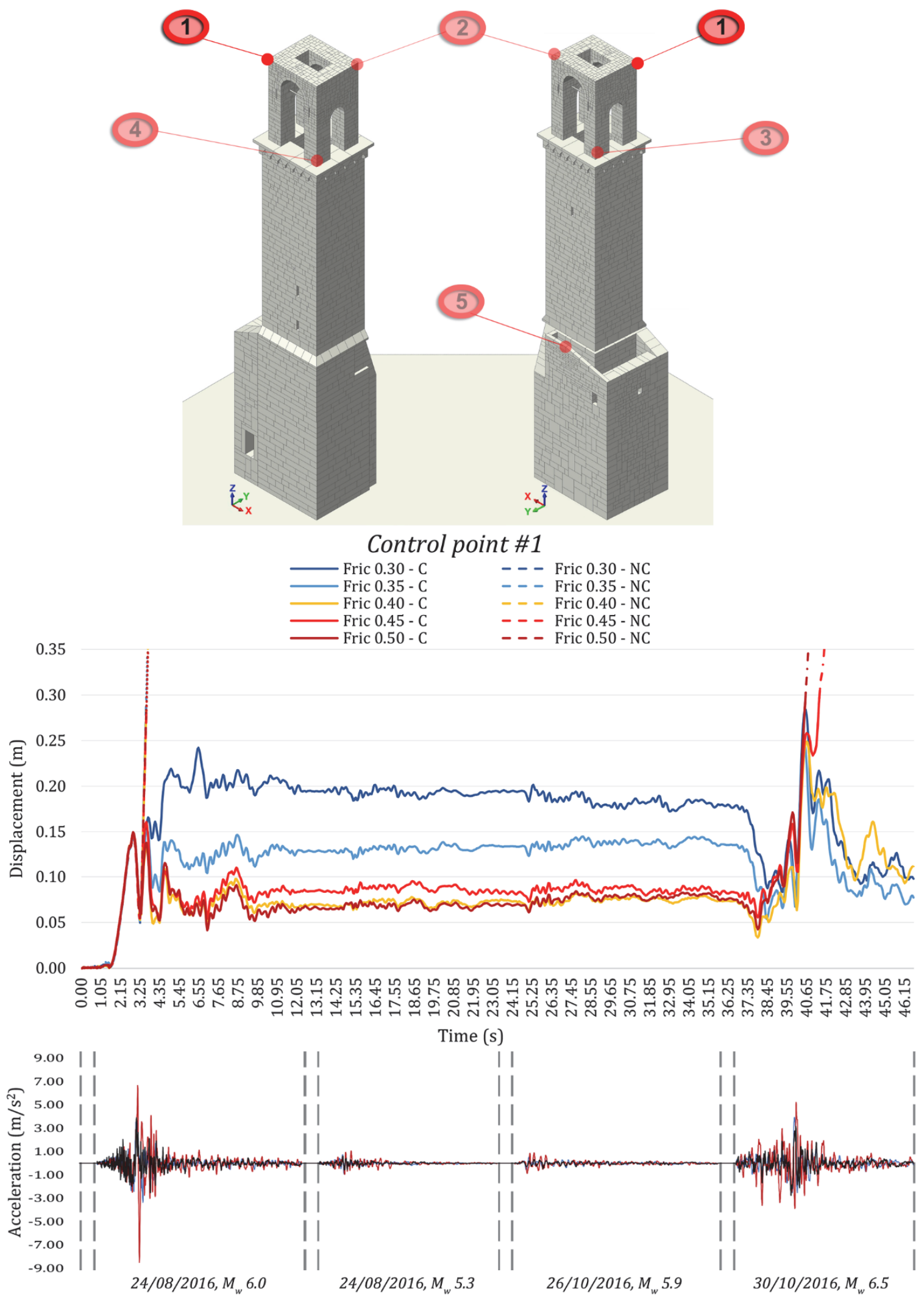

Figure 16: Displacements time histories of the control point \#1 of the civic clock tower of Amatrice (Rieti, Italy) under the four main shocks in the three components x,y,z recorded in the village during the Central Italy seismic sequence of 2016 for both configurations, with (namely $\mathrm{C}$ ) and without (NC) the steel chains, at varying of the friction on the bell cell. 


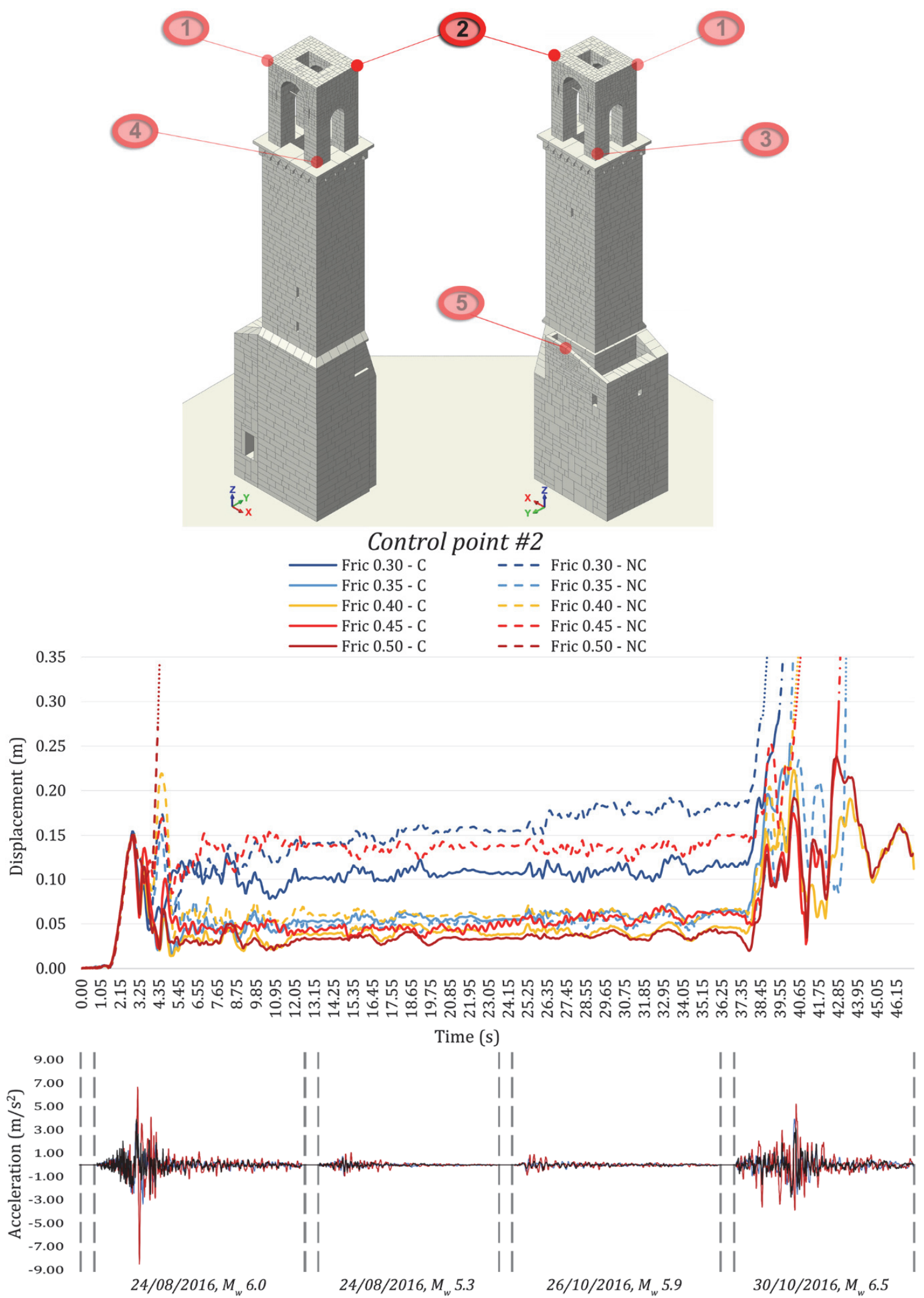

Figure 17: Displacements time histories of the control point \#2 of the civic clock tower of Amatrice (Rieti, Italy) under the four main shocks in the three components x,y,z recorded in the village during the Central Italy seismic sequence of 2016 for both configurations, with (namely $\mathrm{C}$ ) and without (NC) the steel chains, at varying of the friction on the bell cell. 


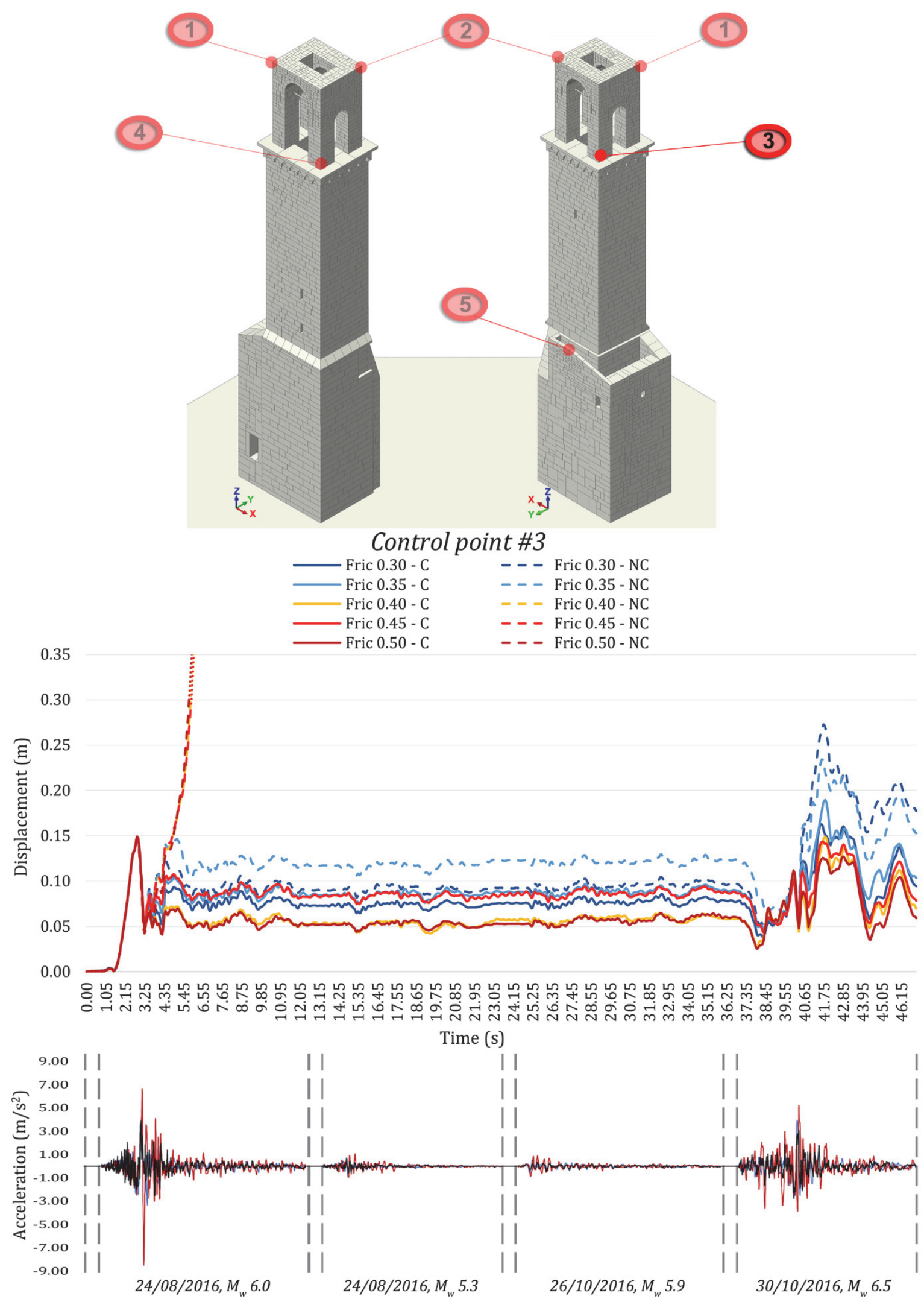

Figure 18: Displacements time histories of the control point \#3 of the civic clock tower of Amatrice (Rieti, Italy) under the four main shocks in the three components x,y,z recorded in the village during the Central Italy seismic sequence of 2016 for both configurations, with (namely $\mathrm{C}$ ) and without (NC) the steel chains, at varying of the friction on the bell cell. 


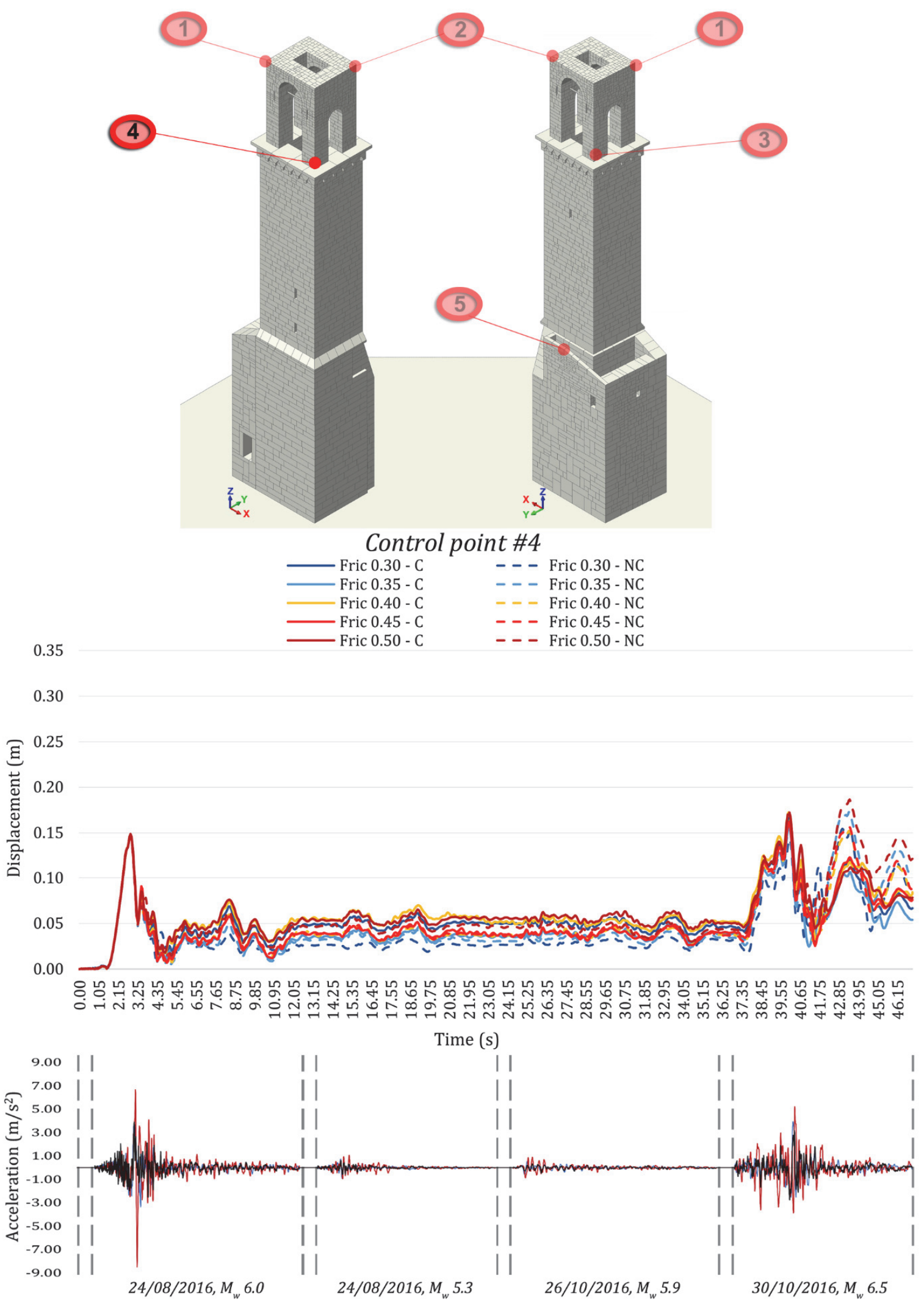

Figure 19: Displacements time histories of the control point \#4 of the civic clock tower of Amatrice (Rieti, Italy) under the four main shocks in the three components x,y,z recorded in the village during the Central Italy seismic sequence of 2016 for both configurations, with (namely $\mathrm{C}$ ) and without $(\mathrm{NC})$ the steel chains, at varying of the friction on the bell cell. 


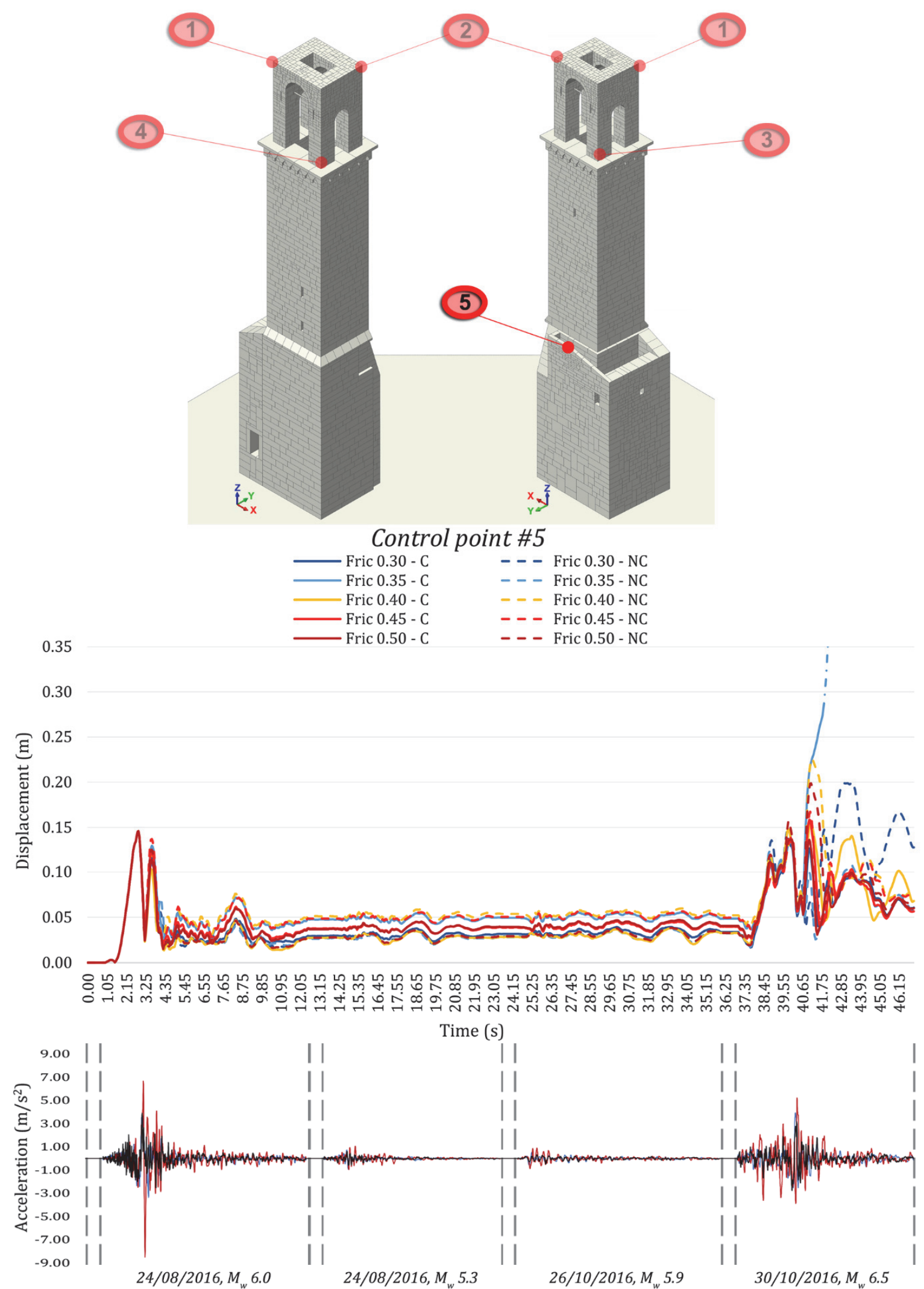

Figure 20: Displacements time histories of the control point \#5 of the civic clock tower of Amatrice (Rieti, Italy) under the four main shocks in the three components x,y,z recorded in the village during the Central Italy seismic sequence of 2016 for both configurations, with (namely $\mathrm{C}$ ) and without (NC) the steel chains, at varying of the friction on the bell cell. 


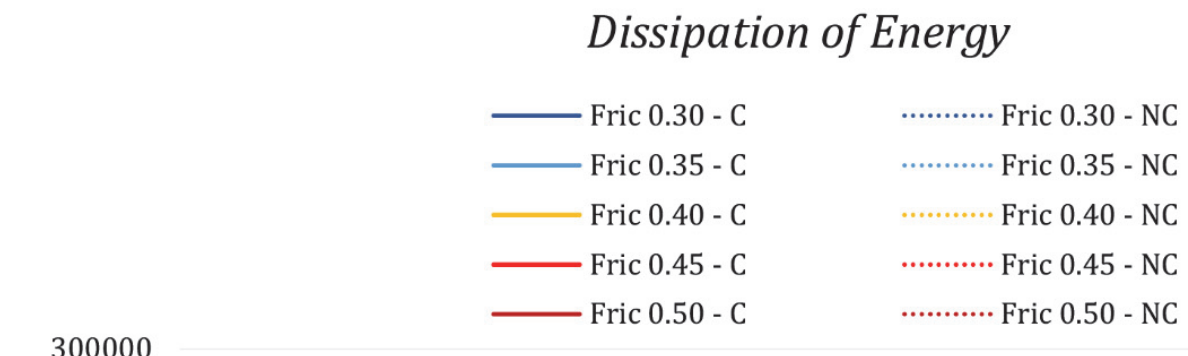

250000

ప્心 200000

100000

50000

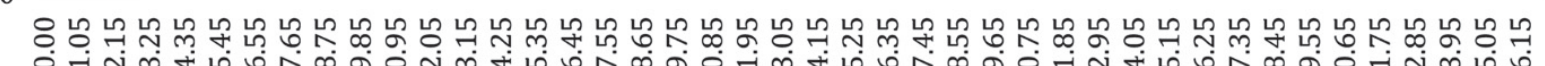
近光 Time (s)

Figure 21: Evolution of the dissipated energy of the civic clock tower of Amatrice (Rieti, Italy) under the four main shocks in the three components $\mathrm{x}, \mathrm{y}, \mathrm{z}$ recorded in the village during the Central Italy seismic sequence of 2016 for both configurations, with (namely C) and without (NC) the steel chains, at varying of the friction on the bell cell.

\section{CONCLUSIONS}

$\checkmark$ he numerical assessment of the iconic crumbling of the clock tower of Amatrice (Rieti, Italy) stroked by Central Italy seismic sequence of 2016, is here briefly reported and summarized, underlining failure mechanisms of this peculiar structure, especially at the upper level, and the incidence of the different possible variables, first of all the quality of the masonry.

To gain a complete comprehension of the mechanical response of such complex ancient structures to seismic loading, focusing on the portions that were damaged the most during the seismic actions, a discontinuous approach with the NSCD method was used, implemented in the $\mathrm{LMGC} 90^{\circ}$, combining modelling simplicity and great predictive capabilities. 
Its simplicity comes from the following fundamental simplifying assumptions: (i) block rigidity; (ii) simple contact laws between blocks; (iii) absence of any damping. As a result, the mechanical behaviour of the masonry structures is influenced by only the friction coefficient, related to the quality of existing masonry of the analysed bell tower. This is a significant consequence for modelling cultural heritage since the determination of the mechanical properties is always uncertain and variable. Despite its simplicity, the model can predict a large variety of dynamical behaviours of historical structures and their seismic vulnerability. Different failure mechanisms may be found, depending on the value assigned to the friction coefficient. In this case study, the value of the friction of the bell cell was varied to represent the current state of the masonry walls and other probable future situations. Moreover, the resistant action of the steel chains was related to the action of different values of the friction, pointing out its relevance. Thus, it was possible to obtain coherent collapse mechanisms and good matching with the real state of the structure and also to predict other potential damages at varying of the masonry mechanical properties.

Finally, the sensitivity of the result to the input parameters is pointed out as consequence of the model's non-smoothness. This character is also present in real structures. Indeed, small irregularities in buildings (especially ancient buildings) affect the seismic response in a visible way. However, the overall behaviours (failure mechanisms) of the analysed macro-elements only gradually change along with the parameters. For instance, if the friction coefficient increased, the overturning mechanisms become gradually prevailing over sliding mechanisms. This represents the main outcomes to understand the behaviour of existing ancient structures.

Another purpose of this work is to suggest retrofitting works according to NSCD numerical results and to highlight that sensitivity to data is less evident in the standard FEM continuum models and represents a further distinguishing feature of the proposed approach. Finally, the need of inserting steel chains is confirmed to be fundamental for medium-high values of friction coefficients as pointed out by numerical results, and furthermore the study shows how important it is to improve the performance of the mortar in order to ensure a monolithic behaviour under the action of sliding associated with mediumlow mortar resistance values.

Other sensitivity analyses are left for future works where the deformability of the blocks and the cohesive zone model should be used instead of rigid blocks and Coulomb's friction law.

\section{REFERENCES}

[1] Lagomarsino, S., Podesta', S. (2004). Damage and Vulnerability Assessment of Churches after the 2002 Molise, Italy, Earthquake, Earthq. Spectra, 20(S1), pp. s271-283, DOI: 10.1193/1.1767161.

[2] Milani, G. (2013). Lesson learned after the Emilia-Romagna, Italy, 20-29 May 2012 earthquakes: A limit analysis insight on three masonry churches, Eng. Fail. Anal., 34, pp. 761-778, DOI: 10.1016/j.engfailanal.2013.01.001.

[3] Brandonisio, G., Lucibello, G., Mele, E., Luca, A. De. (2013). Damage and performance evaluation of masonry churches in the 2009 L'Aquila earthquake, Eng. Fail. Anal., 34, pp. 693-714, DOI: 10.1016/j.engfailanal.2013.01.021.

[4] Valente, M., Milani, G. (2019). Damage assessment and collapse investigation of three historical masonry palaces under seismic actions, Eng. Fail. Anal., 98, pp. 10-37, DOI: 10.1016/j.engfailanal.2019.01.066.

[5] Pellegrini, D., Girardi, M., Lourenço, P.B., Masciotta, M.G., Mendes, N., Padovani, C., Ramos, L.F. (2018). Modal analysis of historical masonry structures: Linear perturbation and software benchmarking, Constr. Build. Mater., 189, pp. 1232-1250, DOI: 10.1016/j.conbuildmat.2018.09.034.

[6] Formisano, A., Vaiano, G., Fabbrocino, F., Milani, G. (2018). Seismic vulnerability of Italian masonry churches: The case of the Nativity of Blessed Virgin Mary in Stellata of Bondeno, J. Build. Eng., 20, pp. 179-200, DOI: 10.1016/j.jobe.2018.07.017.

[7] Milani, G., Valente, M. (2015). Failure analysis of seven masonry churches severely damaged during the 2012 EmiliaRomagna (Italy) earthquake: Non-linear dynamic analyses vs conventional static approaches, Eng. Fail. Anal., 54, pp. 13-56, DOI: 10.1016/j.engfailanal.2015.03.016.

[8] Clementi, F., Quagliarini, E., Monni, F., Giordano, E., Lenci, S. (2017). Cultural Heritage and Earthquake: The Case Study of in Ascoli Piceno, Open Civ. Eng. J., 11(Suppl-5, M5), pp. 1079-1105, DOI: 10.2174/1874149501711011079.

[9] Quagliarini, E., Maracchini, G., Clementi, F. (2017). Uses and limits of the Equivalent Frame Model on existing unreinforced masonry buildings for assessing their seismic risk: A review, J. Build. Eng., 10, pp. 166-182, DOI: 10.1016/j.jobe.2017.03.004.

[10] Clementi, F., Gazzani, V., Poiani, M., Mezzapelle, P.A., Lenci, S. (2018). Seismic Assessment of a Monumental Building through Nonlinear Analyses of a 3D Solid Model, J. Earthq. Eng., 22(sup1), pp. 35-61, DOI: $10.1080 / 13632469.2017 .1297268$. 
[11] Sarhosis, V., Milani, G., Formisano, A., Fabbrocino, F. (2018). Evaluation of different approaches for the estimation of the seismic vulnerability of masonry towers, Bull. Earthq. Eng., 16(3), pp. 1511-1545, DOI: $10.1007 /$ s10518-017-0258-8.

[12] Formisano, A., Massimilla, A. (2018). A Novel Procedure for Simplified Nonlinear Numerical Modeling of Structural Units in Masonry Aggregates, Int. J. Archit. Herit., 12(7-8), pp. 1162-1170, DOI: 10.1080/15583058.2018.1503365.

[13] Sarhosis, V., Bagi, K., Lemos, J. V., Milani, G. (2016). Computational Modeling of Masonry Structures Using the Discrete Element Method, IGI Global.

[14] Sarhosis, V., Lemos, J.V. (2018). A detailed micro-modelling approach for the structural analysis of masonry assemblages, Comput. Struct., 206, pp. 66-81, DOI: 10.1016/j.compstruc.2018.06.003.

[15] Pierdicca, A., Clementi, F., Isidori, D., Concettoni, E., Cristalli, C., Lenci, S. (2016). Numerical model upgrading of a historical masonry palace monitored with a wireless sensor network, Int. J. Mason. Res. Innov., 1(1), pp. 74, DOI: 10.1504/IJMRI.2016.074748.

[16] Maio, R., Vicente, R., Formisano, A., Varum, H. (2015). Seismic vulnerability of building aggregates through hybrid and indirect assessment techniques, Bull. Earthq. Eng., 13(10), pp. 2995-3014, DOI: 10.1007/s10518-015-9747-9.

[17] Asteris, P.G., Sarhosis, V., Mohebkhah, A., Plevris, V., Papaloizou, L., Komodromos, P., Lemos, J. V. (2015).Numerical Modeling of Historic Masonry Structures. In: Asteris, P., Plevris, V., (Eds.), Handbook of Research on Seismic Assessment and Rehabilitation of Historic Structures, Hershey, PA, IGI Global, pp. 213-256.

[18] Pantò, B., Cannizzaro, F., Caddemi, S., Caliò, I. (2016). 3D macro-element modelling approach for seismic assessment of historical masonry churches, Adv. Eng. Softw., 97, pp. 40-59, DOI: 10.1016/J.ADVENGSOFT.2016.02.009.

[19] Moreau, J.J. (1988).Unilateral Contact and Dry Friction in Finite Freedom Dynamics. Nonsmooth Mechanics and Applications, Vienna, Springer Vienna, pp. 1-82.

[20] Chetouane, B., Dubois, F., Vinches, M., Bohatier, C. (2005). NSCD discrete element method for modelling masonry structures, Int. J. Numer. Methods Eng., 64(1), pp. 65-94, DOI: 10.1002/nme.1358.

[21] Clementi, F., Pierdicca, A., Milani, G., Gazzani, V., Poiani, M., Lenci, S. (2018).Numerical model upgrading of ancient bell towers monitored with a wired sensors network. In: Milani, G., Taliercio, A., Garrity, S., (Ed.), 10th International Masonry Conference (IMC_10), Milano, pp. 1-11.

[22] Ferrante, A., Clementi, F., Milani, G. (2019). Dynamic Behavior of an Inclined Existing Masonry Tower in Italy, Front. Built Environ., 5, DOI: 10.3389/fbuil.2019.00033.

[23] Clementi, F., Ferrante, A., Giordano, E., Dubois, F., Lenci, S. (2019). Damage assessment of ancient masonry churches stroked by the Central Italy earthquakes of 2016 by the non-smooth contact dynamics method, Bull. Earthq. Eng., DOI: $10.1007 /$ s10518-019-00613-4.

[24] Dubois, F., Acary, V., Jean, M. (2018). The Contact Dynamics method: A nonsmooth story, Comptes Rendus Mécanique, 346(3), pp. 247-262, DOI: 10.1016/j.crme.2017.12.009.

[25] Lemos, J. V. (2007). Discrete Element Modeling of Masonry Structures, Int. J. Archit. Herit., 1(2), pp. 190-213, DOI: $10.1080 / 15583050601176868$.

[26] Circolare Ministeriale n. 617. (2009). Cons. Sup. LL. PP., “Istruzioni per l'applicazione delle Nuove Norme Tecniche per le Costruzioni” di cui al decreto ministeriale del 14.01.2008. G.U. del 26.02.2009 n. 47, supplemento ordinario n. 27. (in Italian), ,

[27] Vasconcelos, G., Lourenço, P.B. (2009). Experimental characterization of stone masonry in shear and compression, Constr. Build. Mater., 23(11), pp. 3337-3345, DOI: 10.1016/j.conbuildmat.2009.06.045.

[28] Luzi, L., Pacor, F., Puglia, R. (2017). Italian Accelerometric Archive v 2.3, Rome.

[29] Luzi, L., Hailemikael, S., Bindi, D., Pacor, F., Mele, F., Sabetta, F. (2008). ITACA (ITalian ACcelerometric Archive): A Web Portal for the Dissemination of Italian Strong-motion Data, Seismol. Res. Lett., 79(5), pp. 716-722, DOI: 10.1785 /gssrl.79.5.716.

[30] Pacor, F., Paolucci, R., Luzi, L., Sabetta, F., Spinelli, A., Gorini, A., Nicoletti, M., Marcucci, S., Filippi, L., Dolce, M. (2011). Overview of the Italian strong motion database ITACA 1.0, Bull. Earthq. Eng., 9(6), pp. 1723-1739, DOI: $10.1007 /$ s10518-011-9327-6. 